\title{
WestVirginiaUniversity
}

THE RESEARCH REPOSITORY @ WVU

Graduate Theses, Dissertations, and Problem Reports

2004

\section{Maternal diabetes and perinatal outcomes}

Rachael E. Gainor

West Virginia University

Follow this and additional works at: https://researchrepository.wvu.edu/etd

\section{Recommended Citation}

Gainor, Rachael E., "Maternal diabetes and perinatal outcomes" (2004). Graduate Theses, Dissertations, and Problem Reports. 1962.

https://researchrepository.wvu.edu/etd/1962

This Thesis is protected by copyright and/or related rights. It has been brought to you by the The Research Repository @ WVU with permission from the rights-holder(s). You are free to use this Thesis in any way that is permitted by the copyright and related rights legislation that applies to your use. For other uses you must obtain permission from the rights-holder(s) directly, unless additional rights are indicated by a Creative Commons license in the record and/ or on the work itself. This Thesis has been accepted for inclusion in WVU Graduate Theses, Dissertations, and Problem Reports collection by an authorized administrator of The Research Repository @ WVU. For more information, please contact researchrepository@mail.wvu.edu. 


\title{
MATERNAL DIABETES AND PERINATAL OUTCOMES
}

\author{
Rachael E. Gainor
}

A Thesis Submitted to the

Davis College of Forestry, Agriculture and Family and Consumer Sciences

in partial fulfillment of the requirements for the degree of

\section{Master of Science}

In

Child Development and Family Studies

Cindy Fitch, Ph.D., Chair

Carol Markstrom, Ph.D.

Cecil Pollard, M.S.

Department of Family and Consumer Sciences

Morgantown, West Virginia

2004

Keywords: Gestational, Apgar Scores, Macrosomia 


\section{ABSTRACT \\ MATERNAL DIABETES AND PERINATAL OUTCOMES A MASTER'S THESIS}

by

Rachael E.Gainor

Diabetes is a serious problem in the nation and in the state of West Virginia (WV). Having diabetes during pregnancy has been associated with several negative perinatal outcomes. This study was done to test the hypothesis that women with diabetes would have more negative perinatal outcomes than those who do not. A secondary hypothesis was women with pregestational diabetes would have more negative perinatal outcomes than women with gestational diabetes.

This was a population-based study with a causal-comparative (ex post facto) research design using secondary data analysis. The independent variables were the presence or absence of diabetes as well as type of diabetes in the mothers. The dependent variable was perinatal outcomes.

Data were analyzed for the years 2001 and 2002 on all babies born to mothers enrolled in the West Virginia Medicaid program. Data for those two years were analyzed using three different databases including WV Vital Statistics, the WV Birth Score Project and WV Medicaid Claims. There were a total of 14,583 births included in the population. The population was split into two groups according to the presence of diabetes in the mother. This was determined using ICD-9 codes for diabetes in the Medicaid Claims data. The diabetic group consisted of 853 women while the non-diabetic group consisted of 13,750 women. The diabetic group was then divided into those women with pre-gestational diabetes and those women with gestational diabetes. The pre-gestational group consisted of 396 women while the gestational group consisted of 457 women.

The results of this study showed significant associations between the presence of diabetes in mothers and several negative perinatal outcomes including macrosomia, pre-term delivery and less than optimal one-minute Apgar scores. Also, pre-gestational diabetes was shown to be significantly associated with more negative perinatal outcomes than was gestational diabetes. These perinatal outcomes included macrosomia, pre-term birth, less than optimal Apgar scores, occurrence of complications of labor and/or delivery and occurrence of congenital anomalies. 


\section{ACKNOWLEDGEMENTS}

I would personally like to thank Mary Swim, Cecil Pollard and Trisha Petitte from the West Virginia University Office of Health Services Research for contributing their time, effort and support on this thesis. I would also like to give my thanks to Cris Britton for allowing me to use data from the West Virginia Birth Score Project. Cris also contributed much time and effort in helping me to organize and comprehend the data. 
TABLE OF CONTENTS

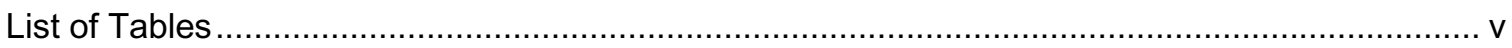

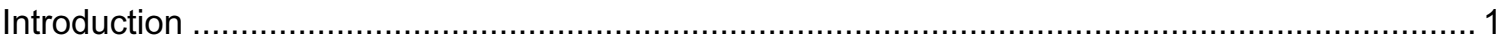

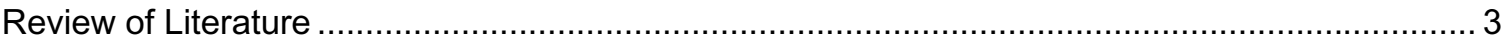

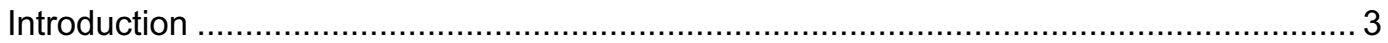

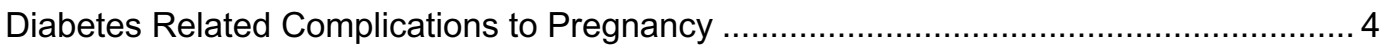

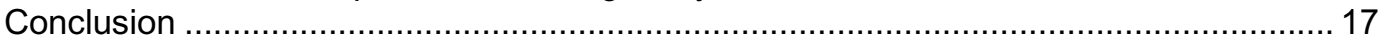

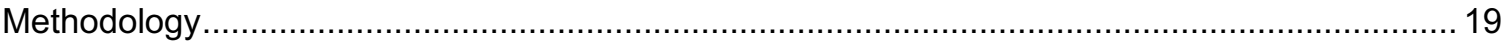

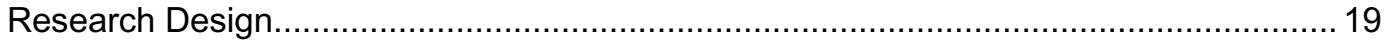

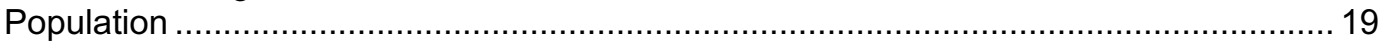

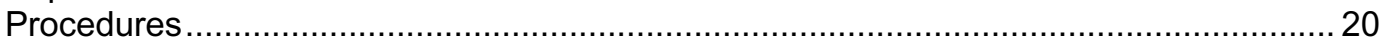

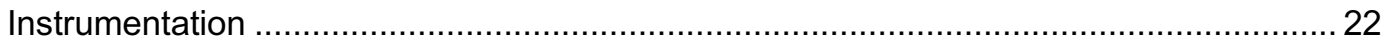

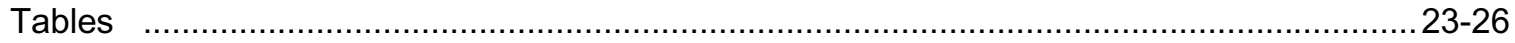

Results 27

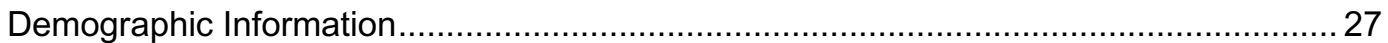

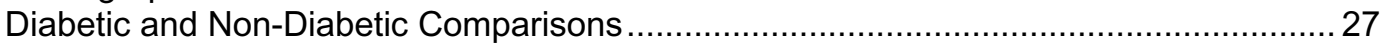

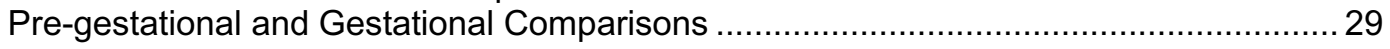

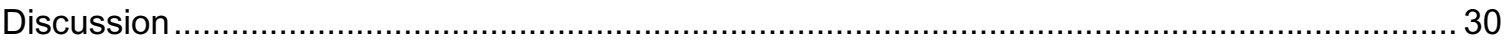

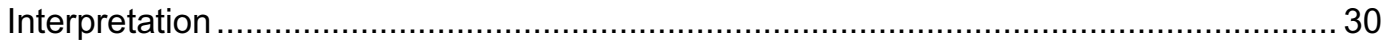

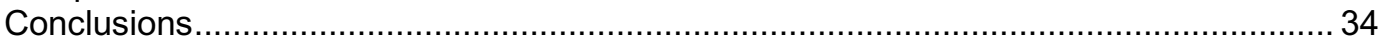

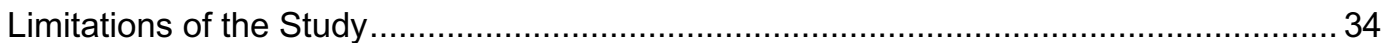

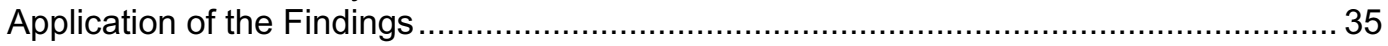

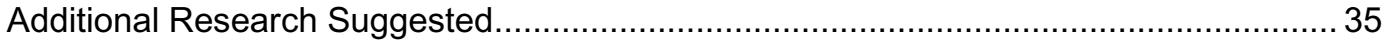

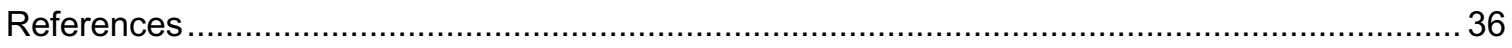

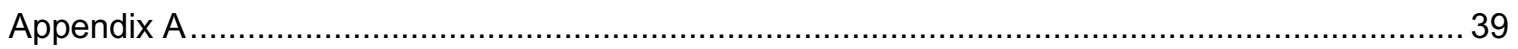

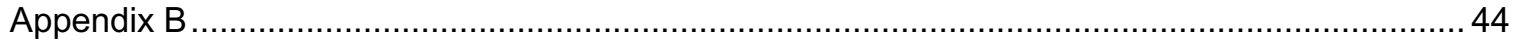

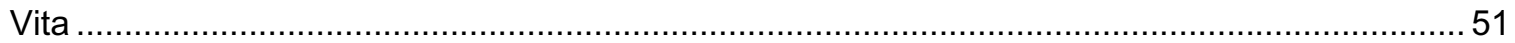




\section{LIST OF TABLES}

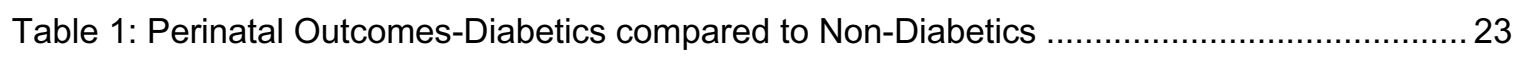

Table 2: Medical Risk Factors-Diabetics compared to Non-Diabetics...................................... 24

Table 3: Perinatal Outcomes-Pre-gestational compared to Gestational Diabetes ........................ 25

Table 4: Medical Risk Factors-Pre-gestational compared to Gestational Diabetes ...................... 26 


\section{INTRODUCTION}

\section{Overview}

The purpose of this study was to research and analyze the effects of maternal diabetes on perinatal outcomes. It was hypothesized that in West Virginia women, pregnancies complicated by maternal diabetes are linked to more negative perinatal outcomes than are pregnancies to mothers without diabetes. A secondary hypothesis analyzed was that Type 1 and Type 2 diabetes (pregestational) are associated with more severe negative perinatal outcomes than is gestational diabetes (GDM). Three statewide databases were analyzed to test these hypotheses. These databases included the West Virginia Vital Registration, the West Virginia Birth Score Project, and West Virginia Medicaid claims data. Data were analyzed for the combined years of 2001 and 2002.

Justification of the Study

It has been established that diabetes is a serious public health problem in West Virginia. It has also been shown that diabetes complicates many pregnancies in the state (Thoenen, Gravely, Wright \& Spiroff, 2001). Research has shown that diabetes during pregnancy is associated with several negative perinatal complications. Mothers with diabetes and their infants will continue to be at risk for diabetes related complications to pregnancy until better solutions for prevention are found.

Birth outcomes of diabetic mothers compared to non-diabetic mothers were analyzed using the WV Vital Registration data and the WV Birth Score Project data. Negative birth outcomes and their association with a specific type of diabetes were analyzed using Medicaid claims data. Analyzing data from all three of these databases and comparing the results will be beneficial to future research in this field. Data analyzed in this study will be used in future projects in West Virginia designed to improve the outcomes of pregnancies complicated by pregestational or gestational diabetes.

\section{Statement of the Problem}

There is a lack of state data for West Virginia that compares specific types of birth outcomes of babies born to mothers with diabetes compared to mothers without diabetes. There 
is also a deficiency of research that compares perinatal outcomes of women with pregestational diabetes and GDM with those of non-diabetic women from the same population base.

Purpose of the Study

The purpose of this study was to determine the existence of negative birth outcomes associated with diabetes and to begin to measure the extent of those negative outcomes. In addition, this research compared pregestational diabetes with gestational diabetes to measure any difference between their effects on pregnancy outcomes. This research was done to better help women in West Virginia with diabetes have healthier pregnancies. 


\section{REVIEW OF LITERATURE}

\section{Introduction}

Diabetes has increasingly become a very serious problem in the United States over the last few years and West Virginia is no exception to this. According to the 1999 Behavioral Risk Factor Surveillance System, the prevalence of diabetes in West Virginia has remained high over the last 10 years. In fact, West Virginia ranks fourth highest in the nation in adults who have been told by their doctors that they have diabetes (Thoenen, Gravely, Wright, Spiroff, 2001). It is no surprise then that a large number of pregnancies occurring in the state are in some way complicated by diabetes. West Virginia, as indicated by Thoenen et al. (2001), has the nation's highest percentage of diabetes as a medical risk factor during pregnancy.

A further complicating factor is that diabetes during pregnancy, whether it is pregestational (onset before pregnancy occurs) or gestational (onset during pregnancy), can lead to adverse outcomes for both mother and infant.

What is Diabetes Mellitus?

The definition of diabetes mellitus, according to The Expert Committee on the Diagnosis and Classification of Diabetes Mellitus (2002), is several metabolic diseases characterized by some degree of hyperglycemia. Hyperglycemia, or high levels of blood glucose, is caused by deficiencies in insulin secretion, insulin action, or both. These insulin deficiencies can be caused by a range of pathogenic processes from autoimmune destruction of the beta cells of the pancreas, which make and secrete insulin, to abnormalities that can result in insulin resistance.

Diabetes can lead to several chronic conditions such as cardiovascular complications, neuropathy (disease of the nerves), nephropathy (disease of the kidneys), and retinopathy (disorder of the retina) which is the leading cause of blindness in the United States. There are several non-modifiable risk factors for these problems such as duration of diabetes, age, genetics and race, as well as modifiable risk factors such as glycemic control and hypertension (Franz, 2001).

Diabetes mellitus (DM) is categorized into three main types-type $1 \mathrm{DM}$, type $2 \mathrm{DM}$, and Gestational (GDM). In the Report of the Expert Committee on the Diagnosis and Classification of 
Diabetes Mellitus (2002), up-to-date definitions for each type of diabetes were given. Type 1 DM is classified as a total deficiency in secretion of insulin. Type $2 \mathrm{DM}$, which is much more prevalent, is classified as a combination of resistance to insulin action and inadequate insulin secretion. Type 1 and type 2 DM may be referred to as pregestational diabetes, because diagnosis occurred before pregnancy. GDM is defined as any degree of glucose intolerance with onset or first diagnosis during pregnancy.

\section{Diabetes-Related Complications to Pregnancy}

There are several complications that can occur for both mother and baby when a mother has diabetes during pregnancy. Congenital anomalies are common among infants born to diabetic mothers (American Diabetes Association, 2002; Brydon, Smith, Proffitt, Gee, Holder \& Dunne, 2000; Casson et al., 1997; Dunne, Brydon, Smith \& Gee, 2003; Farrell, Neale \& Cundy, 2002; Harvard, 2002; Langer \& Conway, 2000; Loffredo, Wilson \& Ferencz, 2001; Moore, Singer, Bradlee, Rothman \& Milunsky, 2000; Penny, Mair \& Pearson, 2003; Platt et al., 2002; Sendag, Terek, Itil, Oztekin \& Bilgin, 2001; Thoenen et al., 2001; Uvena-Celbrezze \& Catalano, 2000; Väärasmäki, Gissler, Ritvanen \& Hartikainen, 2002). Fetal loss is another common outcome of diabetic pregnancies (Brydon et al., 2000; Casson et al., 1997; Dunne et al., 2003; Hawthorne, Irgens, \& Lie, 2000; Langer \& Conway, 2000; Lauenborg et al., 2003; Penny et al., 2003; Platt et al., 2002; Uvena-Celebrezze \& Catalano, 2000; Wylie et al., 2002). Types of fetal loss include spontaneous abortion, stillbirth, and perinatal mortality. Excessive fetal growth, referred to as fetal macrosomia or large for gestational age infants, is a common characteristic in infants born to diabetic mothers (American Diabetes Association, 2003; Brown \& Hare, 1995; Brydon et al., 2000; Casson et al., 1997; Davey, 2003; Dunne et al., 2003; Hsu-Hage \& Yang, 1999; Jensen, Sörensen, Feilerg-Jörgensen, Westergaard \& Beck-Nielsen, 2000; Jovanovic, 2001; Lee-Parritz \& Heffner, 1995; Penny et al., 2003; Platt et al., 2002; Svare, Hansen \& Mölsted-Pedersen, 2001; Thoenen et al., 2001; Wylie et al., 2002)). Complications of labor and delivery, such as cesarean section and preterm delivery, occur more often in pregnancies complicated by diabetes compared to those that are not (Blatman \& Barss, 1995; Dunne et al., 2003; Harvard, 2002; Jensen et al., 2000; Svare et al., 2001; Thoenen et al., 2001; Wylie et al., 2002). 
Diabetes during pregnancy can also mean adverse outcomes for the mother.

Pregnancy-induced hypertension occurs more frequently among diabetic mothers than nondiabetic mothers (American Diabetes Association, 2003; Cundy et al., 2002; Dunne et al., 2003; Hsu-Hage \& Yang, 1999; Jensen et al., 2000; Sendag et al., 2001; Sibai et al., 2000; Wylie et al., 2002). Increased severity of preexisting diabetes-related complications is also a maternal complication of a diabetic pregnancy (Brown \& Hare, 1995; Rosen \& Miodovnik, 2000; Thoenen et al., 2001).

The level of risk for and severity of these complications will depend on several factors, some of which include the previous health of the mother and her glycemic control during pregnancy. This review of literature will focus on the complications of maternal diabetes that occur most frequently.

\section{Congenital Anomalies}

Congenital anomaly is defined by Reeder, Martin and Koniak-Griffen (1997) as "an abnormality present at birth," which could mean "the absence of a normal structure, the presence of an abnormal structure, the disruption of the shape, size, or location of a normal structure, or abnormal measurements". Thoenen et al. (2001) states that diabetes ranked second in maternal risk factors for congenital anomalies (sometimes referred to as congenital malformations or defects) in babies born in West Virginia from 1990-1999. These authors as well as Langer and Conway (2000) confirmed that congenital anomalies are a leading cause of perinatal deaths in infants of diabetic mothers. Harvard (2002) stated that, historically, diabetic mothers have had a 3-fold increased risk in having an infant with severe malformations including those of the brain, spinal cord, and lungs. The American Diabetes Association (2002) affirmed that major congenital malformations are the primary cause of death and serious morbidity in the infants of women who have either type $1 \mathrm{DM}$ or type $2 \mathrm{DM}$.

Much research has been done on the association between an increased risk of having an infant with one or more congenital anomalies and having type $1 \mathrm{DM}$ during pregnancy. Platt et al. (2002), in a 5-year population cohort study of 547 pregnancies of women with type 1 DM, found 
that the women with type $1 \mathrm{DM}$ had 6.4 times the risk of having offspring with a congenital anomaly than did the general population.

In a five year population cohort study including 462 pregnancies, 355 of those being “insulin dependent diabetics" (term used for type 1 DM in 1997), Casson et al. (1997) found that infants born to women with "insulin dependent diabetes" had a 10-fold greater risk of congenital malformation than infants in the general population. They found that the greatest number of congenital anomalies in their study were cardiovascular system defects. The authors also reported that the infants with congenital anomalies born to diabetic mothers weighed less than the other infants in the study.

Penny et al. (2003) found similar results in a national population-based study on the outcomes of pregnancies in type $1 \mathrm{DM}$ mothers in Scotland. They looked at 273 pregnancies of women with Type 1 DM. Within the sample they found 13 confirmed congenital anomalies, which is a rate of 60 per 1000 births. This rate was higher than the non-diabetic comparison group. Severe congenital anomalies were detected antenatally in 6 of the 13 pregnancies complicated by congenital anomalies; these included three central nervous system anomalies, two chromosomal anomalies, and one cardiac anomaly. These cases ended in termination of the pregnancy.

In more severe cases of infants born with congenital anomalies, death can be the result even without early termination of the pregnancy. In these cases stillbirth and perinatal mortality are the outcome. In a "first-year of life" surveillance of infants born with congenital anomalies to mothers with Type 1 DM, Väärasmäki et al. (2002) found several adverse outcomes linked to having Type 1 DM during pregnancy. This was a population-based cohort study using data from four national health registers in Finland from 1991-1995. The study included 954 singleton pregnancies complicated by type $1 \mathrm{DM}$. Their results concluded that of 60 births involving congenital anomalies, the rate of death from birth to one year of life was higher among the infants of diabetic mothers compared to infants of non-diabetic mothers. This was especially true in instances of stillborns. Total post-neonatal deaths were four-fold in the diabetic sample. The most common congenital anomalies in this study were cardiac anomalies, while distress due to 
respiratory anomalies was the leading cause for death to the live-born infants. The authors summarized that despite efforts to improve the care of the type $1 \mathrm{DM}$ mothers, the infants born to these women had an increased risk of congenital anomalies, particularly among males.

Several studies have looked at the association between congenital anomalies and having type 2 DM during pregnancy. Dunne et al. (2003) did an analysis of 12 years of outcome data of pregnancy in women with type $2 \mathrm{DM}$. They analyzed data on 182 pregnancies occurring from 1990-2002 using a regional computerized database system. Their results showed that women with type 2 DM were 11 times more likely to have an infant with a congenital malformation than the general population.

In a comparison of 57 mothers with type 2 DM to 196 mothers with type $1 \mathrm{DM}$, Brydon et al. (2000) found that the rate of congenital malformations in live births of type 2 diabetics was double that of type 1 diabetics. The authors of this study point out, however, that the mothers with type $2 \mathrm{DM}$ were older, weighed more and were of greater parity than the mothers with type 1 DM.

A study by Loffredo et al. (2001) reported that pregestational maternal diabetes (includes both type $1 \mathrm{DM}$ and type $2 \mathrm{DM}$ ) is associated with an increased risk of cardiovascular malformations of early embryonic origin.

GDM is not commonly associated with an increased risk for congenital anomalies. In an analysis of 128 consecutive pregnancies complicated by GDM and 138 consecutive pregnancies of non-diabetic controls, Sendag et al. (2001) found no difference in the rate of congenital anomalies between the two groups. In a review of literature on infants of women with GDM, Uvena-Celebrezze and Catalano (2000) reported that within current literature on the topic, infants of women with GDM carry the same risk for congenital anomalies as the non-diabetic population. They did, however, site one study that found an increased risk for anomalies commonly found in infants of type 1 DM mothers in infants of mothers with type 2 DM and GDM. They attributed these cases to possible undiagnosed cases of type $2 \mathrm{DM}$.

Farrell et al. (2002) found similar results when they researched congenital anomalies in the offspring of women with type $1 \mathrm{DM}$, type $2 \mathrm{DM}$, and GDM in pregnancies occurring between 
1985 and 2000 . They found that those women who were likely to have undiagnosed type 2 DM (according to early postpartum oral glucose tolerance tests) had the same rate of congenital anomalies in their offspring as those women with established type 1 or type $2 \mathrm{DM}$. In the remainder of the women with GDM, the rates of congenital anomalies did not differ from the nondiabetic population.

A study by Moore et al. (2000) looked at the risk of congenital defects associated with maternal diabetes and maternal obesity. They found that women who were diabetic, pregestational or gestational, and were obese had a higher rate of infants with congenital defects than those women who were only obese or only diabetic.

To summarize, according to current research, infants born to mothers with either type 1 DM or type $2 \mathrm{DM}$ are at a much higher risk for developing a congenital anomaly than infants born to the nondiabetic population (American Diabetes Association, 2002; Brydon et al., 2000; Casson et al., 1997; Dunne et al., 2003; Harvard, 2002; Langer \& Conway, 2000; Loffredo et al., 2001; Moore et al., 2000; Penny et al., 2003; Platt et al., 2002; Thoenen et al., 2001; Väärasmäki et al., 2002). It has also been stated that infants with congenital anomalies born to women with type 1 $\mathrm{DM}$ are at a higher risk for death from birth to one year of life than infants with congenital anomalies born to non-diabetic mothers (Väärasmäki et al., 2002). Infants born to women with GDM may be at an increased risk for congenital anomalies (Sendag et al., 2001), especially if their mothers have undiagnosed type 2 DM (Uvena-Celbrezze \& Catalano, 2000; Farrell et al., 2002) or are obese (Moore et al., 2002).

Spontaneous Abortion, Stillbirth, and Perinatal Mortality

Although some authors list several terms for fetal loss, spontaneous abortion, stillbirth, and perinatal mortality are the three that are most commonly referred to within current literature. Reeder et al. (1997) defined "spontaneous abortion," sometimes referred to as miscarriage, as an abortion ("termination of the fetus before the age of viability") caused by natural causes. These authors defined "perinatal mortality" as a rate of both fetal and neonatal (from birth through the $1^{\text {st }}$ 28 days of life) deaths. Thomas (1977) defined "stillbirth" as the birth of a dead fetus. 
Maternal type $1 \mathrm{DM}$ is a well-established cause of spontaneous abortion, stillbirths and perinatal mortality. Casson et al. (1997) reported a fourfold increase in perinatal death and a fivefold increase in stillbirths in the type $1 \mathrm{DM}$ group compared to the general population. Platt et al. (2002) found similar results, reporting that the infants of mothers with type 1 DM had an increased rate of 5.1 times for perinatal mortality compared to those infants of the general population. Penny et al. (2003) also found mortality rates higher than those of the background population.

There are many possible explanations for the increase in fetal death among women with type 1 DM. In an audit on stillbirths in women with pregestational type $1 \mathrm{DM}$ between the years 1990-2000, Lauenborg et al. (2003) found that type 1 women experiencing stillbirth were characterized by higher rates of diabetic nephropathy, previous stillbirths, suboptimal glycemic control, smoking and a lower socioeconomic status. Langer and Conway (2000) did a study of level of glycemia, which is the level of sugar or glucose in the blood (Thomas, 1997), and perinatal outcomes. They comment that analysis of cases of fetal death of mothers with pregestational diabetes reveals abnormal glycemic levels of the mother. These authors also stated-, however, that even with optimal glycemic control, any type of diabetes causes an increased risk of perinatal mortality because of the associated risk factors such as hypertension.

Wylie et al. (2002) researched perinatal outcomes after making an attempt to control for several risk factors and reported positive results. After a 10-year study of 300 consecutive pregnancies of 247 women with type $1 \mathrm{DM}$, these researchers found a perinatal mortality rate lower than that of the control population from the same hospital. During this study participants were asked to check their blood glucose levels at least four times a day to ensure optimal glucose control. Insulin needs were carefully monitored and were adjusted as needed by a team of nurses and physicians educated in diabetes care. The women were seen in the clinic 2 or more times a week with all medical and obstetrical decisions being made on an individual basis, not with formal protocols. The authors attributed the lower rate of perinatal mortality to this improved level of care. They also stated that the control group's perinatal mortality rate was higher than that of the Type 1 group because it reflected the high-risk pregnancies common to that hospital. 
Each one of these studies advocated better prenatal care focusing on improvement of glycemic control for women with type $1 \mathrm{DM}$ in order to improve pregnancy outcomes (Casson et al., 1997; Platt et al., 2002; Penny et al., 2003; Lauenborg et al., 2003; Wylie et al., 2002)

Type 2 DM has also been linked to fetal death. In fact, Brydon et al. (2000) found that the live birth rate was lower for type 2 diabetic mothers than for type 1 diabetic mothers in their sample population. The authors also reported that type 2 mothers in their study had double the rate of early pregnancy loss ( $<24$ wks. gestation) than that of type 1 mothers. They attributed these results to lack of attendance for pre-pregnancy care, late booking for antenatal care, and poor glycemic control by mothers with type 2 DM compared with type 1 mothers. These authors stressed the importance of educating women of childbearing age with type $2 \mathrm{DM}$, as well as their healthcare providers, that type $2 \mathrm{DM}$ is just as serious as type $1 \mathrm{DM}$ and should be treated as such with optimal glycemic control and prenatal care.

Dunne et al. (2003) reported similar adverse outcomes of pregnancies complicated by maternal type $2 \mathrm{DM}$. They found that infants of women with type $2 \mathrm{DM}$ had a 2-fold increased risk of being stillborn; a 2.5-fold increased risk of perinatal mortality; a 3.5-fold increased risk of death within the first month after birth; and a 6-fold increased risk of death up to one year compared with the infants from both regional and national figures.

Several studies have looked at the effects on fetal loss by pregestational diabetes, without deciphering between type 1 and type 2 DM. Hawthorne et al. (2000) did one such study. They looked at all pregnancies of women with pregestational diabetes in Norway and England between July 1994 and June 1997. Perinatal mortality in England among infants born to mothers without diabetes during this time period was $10 / 1000$, while perinatal mortality among infants born to mothers with pregestational diabetes was $42.8 / 1000$. These authors found surprising results when they looked at the same statistics in Norway. Perinatal mortality in Norway among infants born to mothers without diabetes was $6.7 / 1000$, while perinatal mortality among those infants born to diabetic mothers was only slightly higher with a rate of $10.4 / 1000$, these findings were significantly lower than the population in England. The authors were unsure about the reasons 
why these rates were so different from one country to another, and concluded by suggesting further research.

GDM is not commonly associated with severe complications such as fetal death. However, Uvena-Celebrezze and Catalano (2000) suggested even though perinatal mortality is most often associated with pregnancies complicated by type $1 \mathrm{DM}$, it does occur in GDM pregnancies as well. They reported that these deaths usually occurred before a diagnosis of glucose intolerance or with very poor glycemic control during the pregnancy.

To summarize, having any type of diabetes during pregnancy carries a risk for spontaneous abortion, stillbirth, and perinatal mortality. Those women who have pregestational diabetes are at an even higher risk for fetal loss. Good glycemic control and prenatal care can significantly lower these risks. (Brydon et al., 2000; Casson et al., 1997; Langer \& Conway, 2000; Lauenborg et al., 2003; Penny et al., 2003; Platt et al., 2002; Wylie et al. 2002). Macrosomia and Large for Gestational Age

Reeder et al. (1997) define macrosomia as "excessive fetal growth" with a "birth weight in excess of 4,000 to 4,500 grams." These authors defined large for gestational age as "a neonate weighing above the $90^{\text {th }}$ percentile for the gestational age. Large for gestational age infants are immature but overgrown and are typical of diabetic mothers." Although these two terms are defined differently, they are often categorized together when birth weight is discussed and are often used interchangeably.

These conditions are related to several complications during labor of the infant. According to Thoenen et al. (2001), excessive fetal growth can cause shoulder dystocia at birth (complication in oversized infants whose large shoulders catch at the pelvic brim or outlet, (Reeder et al., 1997), traumatic birth injury, and/or asphyxia. Current literature consistently associates these conditions with pregnancies complicated by diabetes. Thoenen et al. (2001) stated that from 1990-1999, West Virginia mothers with diabetes had a higher percentage $(17.2 \%)$ of babies weighing more than $4,000 \mathrm{~g}$ than did West Virginia mothers without diabetes $(10.0 \%)$. 
Type 1 DM is associated with an increased risk of macrosomia. Casson et al. (1997) found that macrosomia was more common among the "insulin dependent" diabetic mothers in their study compared to the general population. They also stated that these findings coincided with findings from their review of literature.

Penny et al. (2003) found similar results in their study of pregnancies complicated by type 1 DM. They found that $55 \%$ of their sample weighed above the $90^{\text {th }}$ centile for babies in the Aberdeen, Scotland population. Platt et al. (2002) also found an association between increased fetal weight and type $1 \mathrm{DM}$. Their research results show that after being corrected for gestational age, the birth weight of infants born to mothers with type $1 \mathrm{DM}$ was greater than those infants born to mothers without diabetes. Wylie et al. (2002) found a significantly higher rate of LGA, shoulder dystocia, and birth injury in infants of type 1 mothers. Out of the infants they analyzed over a 10-year period, $22.5 \%$ (61 infants) weighed more than 4,000g and $4.1 \%$ (11 infants) weighed more than $4,500 \mathrm{~g}$.

Much research has linked type 2 DM during pregnancy to increased fetal size. In fact, in a comparison between outcomes of pregnancies complicated by type $2 \mathrm{DM}$ with pregnancies complicated by type 1 DM, Brydon et al. (2000) found that babies born to mothers with type 2 DM were more likely to be born large for gestational age compared to babies born to mothers with type $1 \mathrm{DM}$. They associated the greater fetal size with suboptimal glycemic control as well as increased maternal weight in the type 2 group (mean BMI >31.)

Dunne et al. (2003) found that $28 \%$ of the infants in their analysis of pregnancy in women with type 2 DM were large for gestational age. Nine infants (5.6\%) weighed between 4 and 4.5 $\mathrm{kg}(8.8-9.2 \mathrm{lbs})$ and six $(3.7 \%)$ weighed more than $4.5 \mathrm{~kg}$.

GDM is commonly associated with macrosomia and large for gestational age infants (American Diabetes Association, 2003; Brown \& Hare, 1995; Davey, 2003; Hsu-Hage \& Yang, 1999; Jensen et al., 2000; Jovanovic, 2001; Lee-Parritz \& Heffner, 1995; Svare et al., 2001; Uvena-Celebrezze \& Catalano, 2000). Brown and Hare (1995) as well as Jovanovic (2001) stated that macrosomia is the most common neonatal outcome attributed to gestational diabetes. In a review of literature on GDM, Uvena-Celebrezze and Catalano (2000) stated that macrosomia 
and large for gestational age complicate almost $50 \%$ of all pregnancies in women with GDM. These authors found several possible explanations for excessive fetal growth in infants of women with GDM, including maternal pregravid (pre-pregnancy) weight, maternal weight gain during pregnancy, maternal glucose, amino acid, and lipid levels as well as an increase in infant insulin production due to increased maternal glucose levels. Jensen et al. (2000) found that macrosomia affected $14 \%$ of the infants born to mothers with GDM in their study, compared to only $6 \%$ of infants in the control group. Svare et al. (2001) had similar findings with an increased frequency of macrosomia in infants born to mothers with GDM compared to non-diabetic controls; the increase was not statistically significant, however.

To summarize, diabetes during pregnancy, whether it is type 1, type 2 or GDM is associated with an increased risk for excessive fetal growth (American Diabetes Association, 2003; Brown \& Hare, 1995; Brydon et al., 2000; Casson et al., 1997; Davey, 2003; Dunne et al., 2003; Hsu-Hage \& Yang, 1999; Jensen et al., 2000; Jovanovic, 2001; Lee-Parritz \& Heffner, 1995; Penny et al., 2003; Platt et al., 2002; Svare et al., 2001; Thoenen et al., 2001; Wylie et al., 2002). Several complications of delivery such as shoulder dystocia, birth injury, and asphyxia are common when an infant is larger than normal for gestational age (Thoenen et al., 2001; Wylie et al., 2002). The causes for excessive fetal growth in diabetic pregnancies are still unknown, but possible explanations include maternal weight and maternal glycemic control (Brydon et al., 2000; Uvena-Celebrezze and Catalano, 2000).

Cesarean Section, Induction of Labor and Preterm Delivery

Cesarean delivery, as defined by Reeder et al. (1997), is "delivery of the fetus by an incision through the abdominal and uterine walls". These authors defined induction of labor as "artificial initiation of labor after the fetus is viable". They defined preterm delivery as a spontaneous or therapeutic (early induction of labor by doctor) end of pregnancy after the age of viability, but before the end of full term gestation, which is 37 weeks.

Thoenen et al. (2001) stated: "Women with diabetes are more likely to suffer one or more complications of labor and/or delivery (such as cesarean section, preterm delivery or induction of labor) than are women who do not have diabetes". These researchers found that from 1990- 
$1999,43.3 \%$ of West Virginia women with diabetes had one or more complications of labor and/or delivery compared to $33.0 \%$ of West Virginia women without diabetes having complications of labor and/or delivery.

Wylie et al. (2002) found that the incidence of cesarean delivery was high among mothers with type $1 \mathrm{DM}$. They found that $49 \%$ of the type 1 pregnancies in their study ended in caesarian section, which is comparable to the $45-67 \%$ that was reported in their review of literature. Labor was induced in 188 of the 300 consecutive pregnancies in this study for a variety of reasons, including large for gestational age, macrosomia, hypertension and fetal distress.

Type $2 \mathrm{DM}$ is also associated with higher numbers of complications of labor and delivery as well. Dunne et al. (2003) found a slightly higher number $(95,53 \%)$ of emergency or elective cesarean deliveries than of vaginal deliveries (87, 47\%). Twenty-one of the 95 cesarean deliveries were preceded by early induction of labor.

Cesarean deliveries and early induction of labor were found to be positively correlated with gestational diabetes mellitus (GDM) in a comparison to non-diabetic controls according to Jensen et al., 2000. Their results show that $33 \%$ of the GDM pregnancies were delivered through cesarean section compared to $21 \%$ of non-diabetic pregnancies. They also state that $61 \%$ of the GDM group resulted in an induction of labor compared to only $24 \%$ of the non-diabetic group.

Sendag et al. (2001) found similar results in their study of gestational diabetes and perinatal outcomes. Their results showed that percentages of both cesarean sections and preterm delivery occurred significantly more often in the group with GDM than in the non-diabetic control group.

Svare et al. (2001) found slightly different results in their look at perinatal complications and gestational diabetes mellitus. They found that the GDM group had a significantly higher frequency of induced labor than the non-diabetic controls; however, there were no differences between the amount of cesarean deliveries or pregnancy complications between the two groups.

Often, the increased risk for cesarean and/or preterm delivery is correlated with the higher incidence of large for gestational age infants and macrosomia. As discussed earlier, these complications are more common in the infants of mothers with diabetes. Blatman and Barss, 
1995, stated that maternal diabetes by itself is not a certain indication for cesarean section, however, macrosomia and large for gestational infants along with the associated problem of shoulder dystocia are indications for cesarean section. Harvard (2002) reported that doctors will often induce labor or cesarean section if the fetus seems to be too large for normal vaginal delivery. The results of Brydon et al. (2000) differed from these statements, however. In their comparison of pregnancies complicated by type 1 and type $2 \mathrm{DM}$, they found that even though there was a higher incidence of babies that were large for gestational age in the type 2 group than in the type 1 group, the type 2 group had more vaginal deliveries. However, they did find a significantly higher number of preterm deliveries in the infants born to type 2 mothers than to type 1 mothers.

To review, complications of labor and delivery—namely cesarean section, induction of labor and/or preterm delivery (either spontaneous or medically induced) have been found to be more common in pregnancies complicated by type 1 DM, type 2 DM, or GDM (Blatman \& Barss, 1995; Dunne et al., 2003; Harvard, 2002; Jensen et al., 2000; Svare et al., 2001; Thoenen et al., 2001; Wylie et al., 2002). According to Blatman and Barss (1995) and Harvard (2002), the increased percentage of delivery complications in diabetic pregnancies is linked to the higher percentage of excessively large babies in diabetic pregnancies. There is some debate, however, about this association (Brydon et al., 2000).

Pregnancy-Induced Hypertension

Pregnancy-induced hypertension, according to Reeder et al. (1995), is a syndrome in pregnant women characterized by hypertension, edema, and proteinuria (high levels of protein in the urine.) Eclampsia and preeclampsia are categories of pregnancy-induced hypertension. Pregnancy-induced hypertension has been found to affect women with type 1 DM, type 2 DM and GDM more often than non-diabetic women. Wylie et al. (2002) found that within their sample, $22.0 \%$ of women with type 1 diabetes had pregnancy-induced hypertension, while only $6.3 \%$ of the non-diabetic controls were affected.

In an analysis of pregnancies complicated by type 2 DM, Dunne et al. (2003) found that $19.7 \%$ of women with type 2 DM had pregnancy-induced hypertension and/or preeclampsia 
compared to $10 \%$ of women who were not diabetic. They also found that fetal loss was more common when the mother had pregnancy-induced hypertension/preeclampsia ( $8.7 \%)$ compared to infants of women who did not have pregnancy-induced hypertension/preeclampsia $(2.7 \%)$.

In a comparison between hypertensive disorders of pregnancy between women with type 1 and type 2 DM, Cundy et al. (2002) found that the incidence of hypertension during pregnancy was similar between the two groups of women. They did find, however, that certain aspects of the hypertension differed between type 1 and type 2 women. For instance, women with type 2 DM had more chronic hypertension (diagnosed at $<20$ weeks gestation) than did women with type 1 DM. The impact of hypertension of adverse outcomes of pregnancy was significantly more severe for women with type $1 \mathrm{DM}$ compared to women with type $2 \mathrm{DM}$, though.

Sibai et al. (2000) did not specify between types of diabetes, but found that the frequency of preeclampsia rose with increasing severity of diabetes in women with pregestational diabetes. In this study of 462 women with pregestational diabetes, they also found that the women with preeclampsia in their study had a significantly higher rate of preterm delivery $(56.5 \%)$ compared to those without preeclampsia (33.3\%).

GDM is associated with an increased risk for maternal hypertensive disorders (American Diabetes Association, 2003; Hsu-Hage \& Yang, 1999; Jensen et al., 2000; Sendag et al., 2001). Sendag et al. (2001) found that there was double the amount of women in the GDM group with hypertensive disorders (9.4\%) compared to the non-diabetic controls (4.3\%). Jensen et al. (2000) illustrated similar results of their comparison of pregnancies complicated by GDM compared with non-diabetic controls. GDM patients were treated with diet, tolbutamide, and insulin. Even with treatment there were $19.6 \%$ of women with hypertensive disorders in the GDM group while there were $10.5 \%$ of women with hypertensive disorders in the non-diabetic group.

To summarize, pregnancy-induced hypertension is more common in women with type 1 DM, type $2 \mathrm{DM}$, or GDM compared to women without diabetes. The timing of onset and the impact on adverse outcomes of pregnancy may differ between women with different types of diabetes (Cundy et al., 2002.) 
Preexisting Diabetes-Related Complications

As previously stated, Type 1 and Type $2 \mathrm{DM}$ are linked to several co-morbidities such as cardiovascular disease, neuropathy, nephropathy, and retinopathy. Pregnancy can lead to further complication of these disorders, especially eye and kidney disease (Harvard, 2002; Thoenen et al., 2001). Brown and Hare (1995) stated that these conditions increase the risk for poor gestational outcomes for both mother and baby. Several researchers have suggested that in order to prevent or lessen the effects of these conditions the first important step is early diagnosis, preferably before pregnancy, and the second important step is optimal glycemic control (American Diabetes Association, 2002; Rosenn \& Miodovnik, 2000.)

\section{Conclusion}

Diabetes is a serious problem in West Virginia. In turn, many pregnancies in the state are complicated by the disease (Thoenen et al., 2001). Both pregestational DM and GDM are linked to adverse perinatal outcomes. Type 1 and Type 2 DM have been linked to complications of pregnancy such as congenital anomalies, fetal loss, excessive fetal growth, problems of labor and delivery and maternal hypertension (American Diabetes Association, 2002; Blatman \& Barss, 1995; Brydon et al., 2000; Casson et al., 1997; Cundy et al., 2002; Dunne et al., 2003; Farrell et al., 2002; Harvard, 2002; Hawthorne et al., 2000; Langer \& Conway, 2000; Lauenborg et al., 2003; Loffredo et al., 2001; Moore et al., 2000; Penny et al., 2003; Platt et al., 2002; Sibai et al., 2000; Thoenen et al., 2001; Väärasmäki et al., 2002; Wylie et al., 2002). Pregnancy can also cause pre-existing diabetes related health disorders such as neuropathy, nephropathy, retinopathy, and cardiovascular disorders to be further aggravated (Brown \& Hare, 1995; Rosen and Miodovnik, 2000; Thoenen et al., 2001). GDM is also linked to adverse perinatal outcomes, namely excessive fetal growth, problems of labor and delivery (commonly because of large fetal size) and maternal hypertension (American Diabetes Association, 2003; Brown \& Hare, 1995; Davey, 2003; Hsu-Hang \& Yang, 1999; Jensen et al., 2000; Jovanovic, 2001; Lee-Parritz \& Heffner, 1995; Sendag et al., 2001; Svare et al, 2001; Uvena-Celebrezze \& Catalano, 2000).

The research analyzed in this review lead to the hypothesis that pregnancies complicated by maternal diabetes are linked to more negative perinatal outcomes than are 
pregnancies to mothers without diabetes. A secondary hypothesis tested was that Type 1 and Type 2 diabetes are associated with more severe negative perinatal outcomes than is gestational diabetes.

There is a lack of research for the state of West Virginia that gives an in depth analysis of the association between diabetes and specific types of negative perinatal outcomes. There is also no research for the state of West Virginia and a lack of national data that analyzes the association between specific types of maternal diabetes and perinatal outcomes. A populationbased analysis and comparison of pregnancies of West Virginia women with pregestational and gestational diabetes as well as non-diabetic WV women was done to research these hypotheses. 


\section{METHODOLOGY}

\section{Research Design}

This study was a causal-comparative (ex post facto) research design with secondary data analysis. The independent variable was the presence or absence of diabetes in the mothers. The dependent variable was perinatal outcomes. There was also further analysis on the differences between perinatal outcomes (secondary dependent variable) of women with pregestational diabetes and gestational diabetes (secondary independent variable). There was a primary division of the population into two groups of women. The first group consisted of women with type 1, type 2 or gestational diabetes. The second group consisted of non-diabetic women. The diabetic group was then subdivided into two groups consisting of women with gestational diabetes and women with pregestational diabetes.

Non-modifiable variables controlled for in both groups were: number delivered at birth (only singular births were used) and Medicaid funding (all women in the study were enrolled in Medicaid at the time of their pregnancy). Confounding variables for both groups were maternal glycemic control and maternal weight. Moderating variables analyzed included: sex of the child, age of mother, race of mother, education level of mother, pregnancy history (including number of live births now living and number of live births now dead), month prenatal care began, number of prenatal visits, infant birth weight, clinical estimate of gestational age, one minute and five minute APGAR scores, medical risk factors of the mother (cardiac disease, diabetes, chronic hypertension, pregnancy-induced hypertension, previous infant $>4000 \mathrm{~g}$, previous pre-term or small for gestational age infant, renal disease, tobacco use, and alcohol use), complications of labor and/or delivery, method of delivery, abnormal conditions of the newborn, congenital anomalies, and fetal loss.

\section{Population}

This was a population-based study consisting of all singular births to West Virginia mothers enrolled in Medicaid during the years 2001 and 2002. These births were identified by state-certified birth certificate data from West Virginia Vital Registration Office in the Bureau for 
Public Health. Births were also identified through the West Virginia Birth Score Project, which has collected data from all births in West Virginia hospitals for the two years.

The total number of births in West Virginia for the years 2001 and 2002 was 40,708 . The total number of births for the West Virginia Medicaid population for those two years was 22,257. After controlling for singular births and after matching up I.D. numbers from the Vital Statistics data to the Medicaid data, the total study population consisted of 14,583 women. The nondiabetic group consisted of 13,730 women while the diabetic group consisted of 853 women. The pregestational group consisted of 396 women while the gestational group consisted of 457 women. All demographic information was self-reported by the mothers and included age, race and education level.

\section{Procedures}

Data on 2001 and 2002 West Virginia birth outcomes were from three separate data collections and were obtained through two different sources. One data source was the West Virginia Birth Score Project. This is a project through West Virginia University that collects data on all West Virginia births. These data are collected from all hospitals in the state where births take place. This data set also included West Virginia Vital Statistics, which are data that is collected by the West Virginia Bureau for Public Health on all West Virginia births that have been identified with a state-certified birth certificate. The data from the West Virginia Birth Score Project included all variables listed in the above "research design" section.

The second source of data was West Virginia Medicaid claims data. ID numbers for women enrolled in Medicaid were matched using ID numbers from the West Virginia Birth Score Project. This was done to better identify those women with diabetes and to categorize the women with diabetes as pregestational or gestational.

Diabetes and type of diabetes were identified using the Medicaid claims data and ICD-9 coding. ICD-9 is the International Classification of Diseases, $9^{\text {th }}$ revision (U.S. Department of Health and Human Services, 1991). Medicaid uses these codes to classify its patients' claims. Any women from our population with a Medicaid claim including an ICD-9 code indicating diabetes was included in the diabetes group. The diabetes group was then divided into 
pregestational and gestational by identifying those women whose Medicaid claims included codes for Type 1, Type 2 or Gestational diabetes. Only women with one code for type of diabetes were used. In other words, no women who had claims that overlapped into more than one type of diabetes were used.

Data were analyzed for 28 total variables. The presence of diabetes and type of diabetes were the two variables used to create the groups to be analyzed. Frequencies were run on eight demographic variables (listed above in "population" section) and nine self-reported medical risk factors. The other nine variables analyzed were perinatal outcomes.

The variable "Medical Risk Factors", which was in the WV Vital Statistics data set, included 17 different sub-fields which each represented a different type of medical risk factor selfreported by the mothers. Nine of those fields were analyzed including cardiac disease, diabetes, chronic hypertension, pregnancy induced hypertension, previous infant $>4,000 \mathrm{~g}$, previous preterm or small infant, renal disease, tobacco use and alcohol use.

The perinatal outcomes were analyzed according to the way data were collected for the WV Vital Statistics. The variables were sometimes subdivided into groups that differed from the original data set because different groupings of the variable meant different health outcomes. For example, infant birth weight was divided into three categories according to what Reeder et al. (1997) defined as low-birth weigh infants, $<2,500 \mathrm{~g} / 5.5 \mathrm{lbs}$ and infants with macrosomia, $>4,000 \mathrm{~g} / 8.2 \mathrm{lbs}$. The third category was those infants that fell in between these two groups, 2 , $540 \mathrm{~g} / 5.6 \mathrm{lbs}$. Birth weights for this study were divided into the three categories of $<5 \mathrm{lbs}, 5-8 \mathrm{lbs}$ and $>8$ lbs.

Clinical estimate of gestational age was broken into the two categories, $\geq 37$ weeks and $<37$ weeks. These groupings were created according to what Reeder et al. (1997) called full term, which is 37 weeks.

Apgar scores, which are defined by Reeder et al. (1997) as a scoring system with a maximum score of 10 that rates the condition of a newborn according to heart rate, respiratory effort, muscle tone, reflex irritability, and color. The variable was split into three categories that Reeder et al. (1997) illustrate. A score of 0-3 indicates that the infant is in very poor condition 
and that resuscitation is needed immediately. A score of 4-6 indicates that the infant is in fair condition and needs to be closely monitored. Finally, a score of 7-10 indicates that the infant is in good condition.

The perinatal outcomes of "complications of labor and/or delivery," "congenital anomalies" and "abnormal conditions of the newborn" also contained different sub-fields which each represented a different condition. For these variables a Yes/No frequency was run to compare the number of times women from each of the groups experienced these outcomes. Frequency distributions for each subfield were run in order to find which sub-fields occurred most often in the population. Appendix B shows which complications of labor and/or delivery and which complications of labor and/or delivery and which congenital anomalies were considered during data collection of the WV Vital Statistics.

For "method of delivery" women were placed in either the vaginal delivery category or the cesarean section delivery. This decision was based on the findings from the literature review which state that women with diabetes may be more likely to have cesarean sections than women without diabetes (Blatman \& Barss, 1995; Dunne et al., 2003; Harvard, 2002; Jensen et al., 2000; Svare et al., 2001; Thoenen et al., 2001; Wylie et al., 2002).

Fetal loss was determined by running a frequency on the presence of date of death. There was not a time frame between birth and date of death used. Those infants that had a date of death were categorized as a fetal loss.

All data were analyzed using the Statistical Analysis System (SAS). Frequencies were run on all variables. Chi Squares or Fisher's Exact Tests (when any expected cell size was $<5$ ) were used to compare the diabetic to the non-diabetic group in respect to perinatal outcomes and to compare the pregestational group to the gestational group in respect to perinatal outcomes.

\section{Instrumentation}

Data were used from preexisting databases from the West Virginia Vital Registration, which is recorded from birth certificates, from the West Virginia Birth Score Project, which is compiled from hospital records which are completed at the time of birth, and from West Virginia Medicaid claims data. 
Table 1: Perinatal Outcomes-Diabetics compared to Non-diabetics

\begin{tabular}{|c|c|c|c|c|c|}
\hline \multirow{2}{*}{$\begin{array}{l}\text { Perinatal Outcomes } \\
\qquad(N=14,583)\end{array}$} & \multicolumn{2}{|c|}{$\begin{array}{l}\text { Diabetic } \\
(\mathrm{N}=853)\end{array}$} & \multicolumn{2}{|c|}{$\begin{array}{c}\text { Non-Diabetic } \\
(N=13,730)\end{array}$} & \multirow{2}{*}{$\begin{array}{l}\text { Chi Square } p \text { value/Fisher's } \\
\text { Exact Test }(F E) \text { Pr<= P }\end{array}$} \\
\hline & No. & Row Pct. & No. & Row Pct. & \\
\hline $\begin{array}{c}\text { Birth Weight } \\
<5 \mathrm{lbs}(\mathrm{N}=1251) \\
5-8 \mathrm{Ibs}(\mathrm{N}=9564) \\
>8 \mathrm{lbs}(\mathrm{N}=2912)\end{array}$ & $\begin{array}{c}58 \\
506 \\
229\end{array}$ & $\begin{array}{c}6.80 \\
59.32 \\
26.85\end{array}$ & $\begin{array}{l}1193 \\
9058 \\
2683\end{array}$ & $\begin{array}{c}8.69 \\
65.97 \\
19.54\end{array}$ & $\begin{array}{l}.0559 \\
<.0001 \\
<.0001\end{array}$ \\
\hline $\begin{array}{c}\text { Clinical Estimate of Gestation } \\
\text { Age } \\
<37 \text { weeks }(\mathrm{N}=1634)\end{array}$ & 159 & 18.77 & 1475 & 10.80 & $<.0001$ \\
\hline $\begin{array}{c}1 \text { Min. Apgar } \\
0-3(N=295) \\
4-6(N=848) \\
7-10(N=13403)\end{array}$ & $\begin{array}{r}21 \\
75 \\
756\end{array}$ & $\begin{array}{l}2.46 \\
8.79 \\
88.63\end{array}$ & $\begin{array}{c}274 \\
773 \\
12647\end{array}$ & $\begin{array}{l}2.00 \\
5.63 \\
92.11\end{array}$ & $\begin{array}{l}.3479 \\
.0001 \\
.0003\end{array}$ \\
\hline $\begin{array}{c}5 \text { Min. Apgar } \\
0-3(N=35) \\
4-6(N=164) \\
7-10(N=14346)\end{array}$ & $\begin{array}{c}2 \\
11 \\
839\end{array}$ & $\begin{array}{c}.23 \\
1.29 \\
98.36\end{array}$ & $\begin{array}{c}33 \\
153 \\
13507\end{array}$ & $\begin{array}{l}.24 \\
1.11 \\
98.38\end{array}$ & $\begin{array}{l}1.000 \mathrm{FE} \\
.6377 \\
.9695\end{array}$ \\
\hline $\begin{array}{c}\text { Complications of Labor and/c } \\
\text { Delivery } \\
\text { Yes }(\mathrm{N}=664)\end{array}$ & 48 & 5.63 & 616 & 4.49 & .1210 \\
\hline $\begin{array}{c}\text { Congenital Anomalies } \\
\text { Yes }(\mathrm{N}=45)\end{array}$ & 4 & .47 & 41 & .30 & $.3344 \mathrm{FE}$ \\
\hline $\begin{array}{c}\text { Abnormal Conditions of the } \\
\text { Newborn } \\
\text { Yes }(N=139)\end{array}$ & 8 & .94 & 131 & .95 & .9622 \\
\hline $\begin{array}{c}\text { Method of Delivery } \\
\text { Cesarean Section N=(922) }\end{array}$ & 46 & 5.39 & 876 & 6.38 & .2502 \\
\hline $\begin{array}{c}\text { Fetal Loss } \\
\text { Yes }(\mathrm{N}=102)\end{array}$ & 9 & 1.06 & 93 & .68 & .1990 \\
\hline
\end{tabular}




\section{Table 2: Medical Risk Factors-Diabetics compared to Non-Diabetics}

\begin{tabular}{|c|c|c|c|c|c|}
\hline \multirow{2}{*}{$\begin{array}{l}\text { Medical Risk Factors } \\
\qquad(\mathrm{N}=14,583)\end{array}$} & \multicolumn{2}{|c|}{$\begin{array}{l}\text { Diabetic } \\
(\mathrm{N}=853)\end{array}$} & \multicolumn{2}{|c|}{$\begin{array}{l}\text { Non-Diabetic } \\
(N=13,730)\end{array}$} & \multirow{2}{*}{$\begin{array}{c}\text { Chi-Square } \mathrm{p} \text { value/Fisher's } \\
\text { Exact Test (FE) } \\
\text { Two Sided } \mathrm{Pr}<=\mathrm{P}\end{array}$} \\
\hline & No. & Row Pct. & No. & Row Pct. & \\
\hline $\begin{array}{c}\text { Cardiac Disease } \\
\text { Yes }(\mathrm{N}=24)\end{array}$ & 10 & 1.17 & 14 & .10 & $<.0000 \mathrm{FE}$ \\
\hline $\begin{array}{l}\text { Diabetes } \\
\text { Yes }(N=70)\end{array}$ & 20 & 2.34 & 50 & .36 & $<.0000 \mathrm{FE}$ \\
\hline $\begin{array}{c}\text { Chronic Hypertension } \\
\text { Yes }(\mathrm{N}=155)\end{array}$ & 19 & 2.23 & 136 & .99 & .0006 \\
\hline $\begin{array}{c}\text { Preg. Induced Hypertension } \\
\text { Yes }(\mathrm{N}=41)\end{array}$ & 6 & .70 & 35 & .25 & $.0307 \mathrm{FE}$ \\
\hline $\begin{array}{c}\text { Previous Infant }>\mathbf{4 0 0 0 g} \\
\text { Yes }(\mathrm{N}=163)\end{array}$ & 3 & .35 & 19 & .14 & $.1347 \mathrm{FE}$ \\
\hline $\begin{array}{c}\text { Previous pre-term or small infant } \\
\text { Yes }(\mathrm{N}=163)\end{array}$ & 89 & 10.43 & 74 & .54 & $<.0001$ \\
\hline $\begin{array}{c}\text { Renal Disease } \\
\text { Yes }(\mathrm{N}=36)\end{array}$ & 1 & .12 & 35 & .25 & $.7220 \mathrm{FE}$ \\
\hline $\begin{array}{l}\text { Tobacco Use } \\
\text { Yes }(\mathrm{N}=6036)\end{array}$ & 291 & 34.32 & 5745 & 42.15 & $<.0001$ \\
\hline $\begin{array}{l}\text { Alcohol Use } \\
\text { Yes }(\mathrm{N}=80)\end{array}$ & 8 & .95 & 72 & .53 & $.1434 \mathrm{FE}$ \\
\hline
\end{tabular}


Table 3: Perinatal Outcomes-Pre-Gestational compared to Gestational Diabetes

\begin{tabular}{|c|c|c|c|c|c|}
\hline \multirow[t]{2}{*}{$\begin{array}{l}\text { Perinatal Outcomes } \\
\qquad(\mathrm{N}=853)\end{array}$} & \multicolumn{2}{|c|}{$\begin{array}{l}\text { Pre-Gestational } \\
\qquad(\mathrm{N}=396)\end{array}$} & \multicolumn{2}{|c|}{$\begin{array}{c}\text { Gestational } \\
(\mathrm{N}=457)\end{array}$} & \multirow{2}{*}{$\begin{array}{c}\text { Chi Square } P \text { value/Fisher's } \\
\text { Exact Test(FE) } \\
\text { Two-Sided } \operatorname{Pr}<=P\end{array}$} \\
\hline & No. & Row Pct. & No. & Row Pct. & \\
\hline $\begin{array}{c}\text { Birth Weight } \\
<5 \mathrm{lbs}(\mathrm{N}=58) \\
5-8 \mathrm{lbs}(\mathrm{N}=506) \\
>8 \mathrm{lbs}(\mathrm{N}=229)\end{array}$ & $\begin{array}{c}33 \\
207 \\
124\end{array}$ & $\begin{array}{c}8.33 \\
52.27 \\
31.31\end{array}$ & $\begin{array}{r}25 \\
299 \\
105\end{array}$ & $\begin{array}{c}5.47 \\
65.43 \\
22.98\end{array}$ & $\begin{array}{r}.0976 \\
<.0001 \\
<.0061\end{array}$ \\
\hline $\begin{array}{c}\text { Clinical Estimate of Gestatio } \\
\text { Age } \\
<37 \text { weeks }(N=159)\end{array}$ & 96 & 24.49 & 63 & 13.85 & $<.0001$ \\
\hline $\begin{array}{c}1 \text { Min. Apgar } \\
0-3(N=21) \\
4-6(N=75) \\
7-10(N=756)\end{array}$ & $\begin{array}{c}16 \\
39 \\
341\end{array}$ & $\begin{array}{r}4.04 \\
9.85 \\
86.11\end{array}$ & $\begin{array}{r}5 \\
36 \\
415\end{array}$ & $\begin{array}{l}1.09 \\
7.88 \\
90.81\end{array}$ & $\begin{array}{l}.0056 \\
.3107 \\
.0311\end{array}$ \\
\hline $\begin{array}{c}5 \text { Min. Apgar } \\
0-3(N=2) \\
4-6(N=11) \\
7-10(N=839)\end{array}$ & $\begin{array}{c}1 \\
8 \\
387\end{array}$ & $\begin{array}{l}.25 \\
2.02 \\
97.73\end{array}$ & $\begin{array}{c}1 \\
3 \\
452\end{array}$ & $\begin{array}{c}.22 \\
.66 \\
98.91\end{array}$ & $\begin{array}{l}1.000 \mathrm{FE} \\
.0783 \\
.1766\end{array}$ \\
\hline $\begin{array}{c}\text { Complications of Labor and } \\
\text { Delivery } \\
\text { Yes }(\mathrm{N}=48)\end{array}$ & 30 & 7.58 & 18 & 3.94 & .0215 \\
\hline $\begin{array}{c}\text { Congenital Anomalies } \\
\text { Yes }(N=4)\end{array}$ & 4 & 1.01 & 0 & 0.00 & $.0461 \mathrm{FE}$ \\
\hline $\begin{array}{c}\text { Abnormal Conditions of th } \\
\text { Newborn } \\
\text { Yes }(\mathrm{N}=8)\end{array}$ & 4 & 1.01 & 4 & .88 & $1.000 \mathrm{FE}$ \\
\hline $\begin{array}{c}\text { Method of Delivery } \\
\text { Cesarean Section } N=(46)\end{array}$ & 17 & 4.29 & 29 & 6.35 & .1856 \\
\hline $\begin{array}{l}\text { Fetal Loss } \\
\text { Yes }(\mathrm{N}=9)\end{array}$ & 7 & 1.77 & 2 & .44 & $.0898 \mathrm{FE}$ \\
\hline
\end{tabular}




\section{Table 4: Medical Risk Factors-Pre-Gestational compared to Gestational Diabetes}

\begin{tabular}{|c|c|c|c|c|c|}
\hline \multirow{2}{*}{$\begin{array}{l}\text { Medical Risk Factors } \\
\qquad(\mathrm{N}=853)\end{array}$} & \multicolumn{2}{|c|}{$\begin{array}{l}\text { Pre-Gestational } \\
\qquad(\mathrm{N}=396)\end{array}$} & \multicolumn{2}{|c|}{$\begin{array}{l}\text { Gestational } \\
(\mathrm{N}=457)\end{array}$} & \multirow{2}{*}{$\begin{array}{c}\text { Chi-Square } \mathrm{p} \text { value/Fisher's } \\
\text { Exact Test (FE) } \\
\text { Two Sided } \mathrm{Pr}<=\mathrm{P}\end{array}$} \\
\hline & No. & Row Pct. & No. & Row Pct. & \\
\hline $\begin{array}{c}\text { Cardiac Disease } \\
\text { Yes }(N=10)\end{array}$ & 7 & 1.77 & 3 & .66 & $.2015 \mathrm{FE}$ \\
\hline $\begin{array}{c}\text { Diabetes } \\
\text { Yes }(N=20)\end{array}$ & 14 & 3.54 & 6 & 1.31 & .0324 \\
\hline $\begin{array}{c}\text { Chronic Hypertension } \\
\text { Yes }(\mathrm{N}=19)\end{array}$ & 8 & 2.02 & 11 & 2.41 & .7026 \\
\hline $\begin{array}{c}\text { Preg. Induced Hypertension } \\
\text { Yes }(\mathrm{N}=6)\end{array}$ & 5 & 1.26 & 1 & .22 & .1019 FE \\
\hline $\begin{array}{c}\text { Previous Infant }>4000 \mathrm{~g} \\
\text { Yes }(\mathrm{N}=3)\end{array}$ & 1 & .25 & 2 & .44 & $1.000 \mathrm{FE}$ \\
\hline $\begin{array}{c}\text { Previous pre-term or small infant } \\
\text { Yes }(\mathrm{N}=89)\end{array}$ & 65 & 16.41 & 24 & 5.25 & $<.0001$ \\
\hline $\begin{array}{c}\text { Renal Disease } \\
\text { Yes }(N=1)\end{array}$ & 1 & .25 & 0 & 0.00 & $.2824 \mathrm{FE}$ \\
\hline $\begin{array}{l}\text { Tobacco Use } \\
\text { Yes }(N=291)\end{array}$ & 131 & 33.33 & 160 & 35.16 & .5754 \\
\hline $\begin{array}{l}\text { Alcohol Use } \\
\text { Yes }(\mathrm{N}=8)\end{array}$ & 1 & .26 & 7 & 1.54 & $.0753 \mathrm{FE}$ \\
\hline
\end{tabular}




\section{RESULTS}

\section{Demographic Information}

Of the total population, $48.57 \%$ of the infants born were female while $51.43 \%$ were male. The non-diabetic group consisted of $48.70 \%$ female infants and $51.30 \%$ male infants while the diabetic group consisted of $46.58 \%$ female infants and $53.42 \%$ male infants.

The range of ages for the total population of women was 14-57 with the mean age being 23.50. The non-diabetic group had an age range of $16-44$ with a mean age of 26.06 while the diabetic group had a larger age range of $14-57$ with a mean age of 23.33 . The majority of the mothers in the study were white making up $94.94 \%$ of the total population. Black mothers made up $3.55 \%$ of the population while "other" races made up .51\% of the population. The variable "highest level of education completed" was broken up into 6 categories. Of the total population of women $3.72 \%$ had no high school education, $27.34 \%$ had some high school education (1-3yrs), $48.80 \%$ graduated from high school, $18.56 \%$ had $1-4$ years of college and $.99 \%$ had $5+$ years of college.

The mothers also reported on pregnancy history and prenatal care. A total of 7,645 $(52 \%)$ of all women in the population had a previous birth of a child who is now living. Two hundred and nineteen women $(.015 \%)$ of women in the population had a previous birth of a child who is now dead. The month prenatal care began was reported using numbers from 0-9 with each number representing that month of pregnancy. The mean for the month that prenatal care began was 2.68 for the total population. The mean number of total prenatal visits was 11.56 for the entire population, 11.47 for the non-diabetic population and 13 for the diabetic population.

\section{Diabetic and Non-Diabetic Comparisons}

The perinatal outcomes of the diabetic group and the non-diabetic group are summarized

in Table 1. The table displays total numbers for each perinatal outcome as well as row percentage according to chi-squares run on each one. The row percentage is the percentage of women in that category with that perinatal outcome. The table also displays $p$ values for comparisons between row percentages in the diabetic group and row percentages in the nondiabetic group. 
Looking at Birth Weight we see that the non-diabetic group had a significantly higher percentage of women who had infants falling in the 5-8lb category than did the diabetic group $(p=<.0001)$. Also shown is that the women in the diabetic group had a significantly higher percentage of babies weighting $>8 \mathrm{lbs}$.

The diabetic group had a significantly higher percentage of infants born before full gestation $(37 w k s)(p=<.0001)$. It is shown that $18.77 \%$ of the diabetic group delivered before 37 weeks while $10.80 \%$ of the non-diabetic group delivered before full term.

There were several significant differences between the two groups in the one-minute Apgar scores but no significant associations were shown between presence of diabetes and fiveminute Apgar scores. The diabetic group had a significantly higher percentage of women who delivered infants with one-minute Apgar scores in the 4-6 range $(p=.0001)$ while the non-diabetic group had a significantly higher percentage of women whose infant's one-minute score was in the $7-10$ range $(p=.0003)$.

When looking at associations between presence of diabetes and complications of labor and/or delivery, congenital anomalies, abnormal conditions of the newborn, method of delivery and fetal loss, there were no significant differences between the diabetic and non-diabetic groups.

Frequency distributions were run to find which complications of labor and/or delivery and which congenital anomalies occurred most often in the entire population. The most frequently occurring complications of labor and/or delivery were use of anesthetic, abruptio placenta, and fever. The most frequently occurring congenital anomalies were cleft lip/palate, "other" circulatory/respiratory problems and anencephalus. There is further explanation of these in the Discussion section.

Table 2 summarizes the self-reported medical risk factors of the diabetic and non-diabetic groups. A significantly higher percentage of the diabetic group reported having cardiac disease $(p=<.0000)$, chronic hypertension $(p=.0006)$, pregnancy-induced hypertension $(p=.0307)$ and previous pre-term or small for gestational infants $(p=<.0001)$ than did the non-diabetic group. The non-diabetic group, however, did report a significantly higher percentage of tobacco use than did the diabetic group $(p=<.0001)$. The non-diabetic group also had a significantly higher 
percentage of women self-reporting that they had diabetes than did the women who were in the diabetes group $(p=<.0000)$.

\section{Pre-gestational and Gestational Comparisons}

As shown in table 3 the gestational group had a significantly higher percentage of women who had babies in the 5-8lb weight range than did the pre-gestational group $(p=<.0001)$. The pre-gestational group had a significantly higher percentage of women who delivered infants who weighed more than $8 \mathrm{lbs}$ than did the women in the gestational group $(p=<.0061)$. The pregestational group also had a significantly higher percentage of women who delivered before full term of 37 weeks (<.0001).

Looking at one-minute Apgar scores we see that the pre-gestational group had a significantly higher percentage of women whose infants were in the $0-3$ range $(p=.0056)$, which according to Reeder, Martin and Koniak-Griffen (1997) means a need for resuscitation of the infant. The Gestational group, however, had a significantly higher percentage of women whose infants fell into the $7-10$ range $(p=.0311)$.

The pre-gestational group had a significantly higher percentage of women who had some type of complication of labor and/or delivery $(p=.0215)$ as well as a significantly higher percentage of women whose infant had a congenital anomaly $(p=.0461)$ than did the gestational group. There were no significant associations shown between type of diabetes and five-minute Apgar scores, abnormal conditions of the newborn, method of delivery or fetal loss.

Table 4 displays the analysis of the self-reported medical risk factors for the pregestational group and the gestational group. The pre-gestational group reported significantly higher percentages of diabetes $(p=.0324)$ and previous pre-term or small infants $(p=<.0001)$ than did the gestational group. 


\section{DISCUSSION}

\section{Interpretation}

Birth weight

Having any type of diabetes during pregnancy is associated with an increased risk for macrosomia (American Diabetes Association, 2003; Brown \& Hare, 1995; Brydon et al., 2000; Casson et al., 1997; Davey, 2003; Dunne et al., 2003; Hsu-Hage \& Yang, 1999; Jensen et al., 2000; Jovanovic, 2001; Lee-Parritz \& Heffner, 1995; Penny et al., 2003; Platt et al., 2002; Svare et al., 2001; Thoenen et al., 2001; Wylie et al., 2002). This was supported in this research study. Looking at table 1 we see a significant association was shown between maternal diabetes and infants with macrosomia. In turn there was a significant association between not having diabetes and delivering a baby that weighed 5-8lbs (normal newborn weight range according to Reeder et al., 1997). This weight range is what these authors suggested is the healthiest range for a newborn to be in.

Table 3 shows that when comparing pre-gestational diabetes and gestational diabetes in relation to birth weight we see macrosomia occurred in both groups of women but occurred significantly more often in the pre-gestational group.

Clinical Estimate of Gestational Age

Pre-term delivery-as well as other complications of labor and delivery- has been more commonly reported in pregnancies complicated by diabetes than in those that are not (Blatman \& Barss, 1995; Dunne et al., 2003; Harvard, 2002; Jensen et al., 2000; Svare et al., 2001; Thoenen et al., 2001; Wylie et al., 2002). Blatman and Barss (1995) and Harvard (2002) attribute this higher incidence of pre-term delivery to a higher percentage of macrosomia in babies of diabetic women. Table 1 shows that in this study both preterm delivery (delivery before 37 weeks gestation) and macrosomia (discussed above) occurred significantly more often in the diabetic group than in the non-diabetic group.

Again, table 3 shows that even though both diabetes groups had occurrences of pre-term delivery, the pre-gestational diabetes group had a significantly higher percentage of babies delivered before 37 weeks than did the gestational group. 
Apgar Scores

Apgar scores were analyzed because they give a rating of health at birth that includes several factors including heart rate, respiratory effort, muscle tone, reflex irritability, and color (Reeder et al., 1997). In table 1 we see that the diabetic group had a significantly higher percentage of newborns falling within the 4-6 score range while the non-diabetic group had a significantly higher percentage falling within the 7-10 range. According to Reeder et al. (1997) in their explanation of Apgar scores, this would mean that significantly more women in the diabetic group had had infants whose score indicated only fair health status and a need for close monitoring. In turn, the women's infants in the non-diabetic group were more likely to be in optimal health score range.

When comparing the Apgar scores of the infants born to the pre-gestational group and the gestational group (table 3), the gestational group had a significantly higher percentage of newborns falling in the 7-10 score range, which again is the most desired outcome when observing Apgar scores. The pre-gestational group did also have a higher percentage of newborns that had scores in the 0-3 range, which indicates a need for resuscitation (Reeder et al., 1997), but it was not a significant difference.

Complications of Labor and/or Delivery

There was no previous research found that supported an association between the complications of labor and delivery accounted for in the WV Vital Statistics database used for this study (see Appendix B) and presence of diabetes in mothers. Thoenen et al. (2001) and Reeder et al. (1997), however, both stated that certain problems of labor and delivery such as shoulder dystocia, traumatic birth injury, and/or asphyxia can occur in mothers whose infant has macrosomia, which a significant percentage of this population did. These complications were not accounted for in the Vital Statistics data.

Out of the total population of 14,583 pregnancies only $664(4.55 \%)$ had some complication of labor and/or delivery. There was no significant difference between the diabetic group and the non-diabetic group in relation to this variable. There were three complications of labor and/or delivery that occurred most often within the population. Use of anesthetic occurred 
in a total of 100 women (.69\%) Abruptio Placenta, which is a premature separation of the implanted placenta and is considered a medical emergency (Reeder et al., 1997) occurred in 85 women $(.58 \%)$. Fever was the third most frequently occurring complication and it occurred in 79 women $(.54 \%)$.

A significantly higher percentage of women in the pregestational group experienced some type of complication of labor and/or delivery compared to the gestational group. The three most frequently occurring complications of labor and/or delivery were the same in the diabetic group as in the total population.

\section{Congenital Anomalies}

Research has shown that an association exists between having pregestational diabetes and delivering an infant with a congenital anomaly (American Diabetes Association, 2002; Brydon et al., 2000; Casson et al., 1997; Dunne et al., 2003; Harvard, 2002; Langer \& Conway, 2000; Loffredo et al., 2001; Moore et al., 2000; Penny et al., 2003; Platt et al., 2002; Thoenen et al., 2001; Väärasmäki et al., 2002). In this study, however, this association was only partially supported. Table 1 shows that there was no significant difference in the percentage of women whose infant had a congenital anomaly when comparing the diabetic population and the nondiabetic population. This could be due to the fact that only $45(.31 \%)$ of the entire population's infants were diagnosed with a congenital anomaly.

There were three congenital anomalies that occurred most often in the entire population including cleft lip/palate, "other" circulatory/respiratory problems and anencephalus. Cleft lip indicates an incomplete closure of the infants lip (Reeder et al., 1997). Other circulatory/respiratory problems would be those problems not specified in the Vital Statistics codes (Appendix B). Anencephalus is defined as a complete or partial absence of the infant brain and skull (Reeder et al., 1997).

There were a significantly higher percentage of women with pre-gestational diabetes $(1.01 \%)$ who had an infant with a congenital anomaly compared to the percentage of women with gestational diabetes who had an infant with a congenital anomaly $(0.00 \%)$. This is supported in research done by Uvena-Celebrezze and Catalano (2000). These authors reported that within 
current literature on the topic, infants of women with GDM carry the same risk for congenital anomalies as the non-diabetic population.

Method of Delivery

A positive association between a need for cesarean section as method of delivery and maternal diabetes has been strongly supported in current literature (Blatman \& Barss, 1995; Dunne et al., 2003; Harvard, 2002; Jensen et al., 2000; Svare et al., 2001; Thoenen et al., 2001; Wylie et al., 2002). However, in this study, this association was not supported. As displayed in table 1, there was no significant difference between the percentages of cesarean section deliveries in the diabetic group compared to the non-diabetic group.

Fetal Loss

Fetal loss through spontaneous abortion, stillbirth, and perinatal mortality has been positively associated with maternal diabetes (Brydon et al., 2000; Casson et al., 1997; Dunne et al., 2003; Hawthorne et al., 2000; Langer and Conway, 2000; Lauenborg et al., 2003; Penny et al., 2003). This association was not supported by this research. Table 1 shows that there was no significant difference between the diabetic group and the non-diabetic group in respect to percentages of fetal loss.

Table 3 displays that there was no difference in percentages of fetal loss between gestational diabetics and pre-gestational diabetics. There was no previous literature found to support this.

Medical Risk Factors

It is known that diabetes is associated with several chronic conditions such as renal disease, retinopathy, cardiovascular disease, and neuropathy. It is also known that tobacco use and hypertension can increase the risk of these conditions (Franz, 2001). Pregnancy itself can lead to further complication of retinopathy and renal disease (Harvard, 2002; Thoenen et al., 2001). These conditions have also been found to increase the risk for poor gestational outcomes for both mother and baby (Brown and Hare, 1995).

The above information is why the seven self-reported medical risk factors were analyzed in this study. Another reason for analysis was to show what percentages of women were 
experiencing these risk factors and how many women were actually reporting them for state data collection. Significantly more women with diabetes reported cardiac disease, diabetes, chronic hypertension, pregnancy induced hypertension and/or previous pre-term or small infants than did those women without diabetes. There was also a significantly higher percentage of non-diabetic women who used tobacco during their pregnancy compared to those women who were diabetic. A surprisingly high percentage $(41.69 \%)$ of women in the total population reported using tobacco during their pregnancy.

\section{Conclusions}

It was hypothesized that in West Virginia women, pregnancies complicated by maternal diabetes are linked to more negative perinatal outcomes than are pregnancies not complicated by diabetes. This hypothesis was partially supported in this research. Although there were not necessarily "more" negative perinatal outcomes in the diabetic group, there were several perinatal outcomes that were significantly more associated with the diabetes group than with the nondiabetic group. These perinatal outcomes included macrosomia, pre-term delivery, and infants with 4-6 range Apgar scores.

A secondary hypothesis analyzed was that Type 1 and Type 2 diabetes (pregestational) are associated with more severe negative perinatal outcomes than is gestational diabetes (GDM). This hypothesis was supported in that macrosomia, per-term delivery, lower Apgar scores, complications of labor and/or delivery, and congenital anomalies all occurred significantly more often in the pre-gestational group than in the gestational group.

\section{Limitations of the Study}

There were several limitations of this study. The medical risk factors used were selfreported by the mothers. The category "diabetes" shows that discrepancies did exist between facts and the data collected from the birth certificates. WV Medicaid claims data showed that of the 14,583 women in our study, 853 of them were diabetic. Only 20 of the women in the diabetic group (according to the Medicaid data) reported that they had diabetes on their child's birth certificate. Of the non-diabetic group, 50 women reported that they had diabetes on their child's birth certificate. 
Another limitation of the study was that the data collected by WV Vital Statistics did not include all information that I wished to include in my study. For example, several complications of labor and/or delivery were found to be positively associated with diabetes in the review of literature, but they were not included within Vital Statistics data collection (discussed in Discussion section).

One final limitation of this study is that because the women in this study were all enrolled in Medicaid, the results cannot be generalized to the entire West Virginia population or to the entire diabetes population. Research has shown that socioeconomic status is positively associated with health status (Adler and Ostrove, 1999; "Socioeconomic Condition", 1999). This means that due to the lower socioeconomic status of the population in this study (Medicaid patients) their health status may be poorer than that of that general population.

\section{Application of the Findings}

The goals of this research were to determine the existence of negative birth outcomes associated with diabetes and to begin to measure the extent of those negative outcomes. This goal was achieved. This research can be used to implement future projects to help West Virginia women with diabetes to have healthier pregnancies.

\section{Additional Research Suggested}

This research has supported the hypothesis that several perinatal outcomes including birth weight, pre-term delivery, Apgar scores, complications of labor and delivery, as well as congenital anomalies are significantly more common in women with pre-gestational diabetes than in those with gestational diabetes. However, there is a lack of research available that compares associations between perinatal outcomes and type of diabetes. In order to further support this hypothesis, more research (such as prospective-longitudinal studies) is needed on the topic. 


\section{REFERENCES}

Adler, N. E., \& Ostrove J. M. (1999). Socioeconomic status and health: what we know and what we don't. Ann N Y Acad Sci., 896, 3-15

American Diabetes Association. (2002). Preconception care of women with diabetes. Diabetes Care, 25(Suppl. 1), S82-S4.

American Diabetes Association. (2003). Gestational diabetes mellitus. Diabetes Care, 26(Suppl. 1), S103-S105.

Blatman, R. N., \& Barss, V. A. (1995). Obstetrical management. In F. M. Brown \& J. W. Hare (Eds.), Diabetes Complicating Pregnancy: The Joslin Clinic Method (pp.139-149). New York: Wiley-Liss, Inc.

Brown, F. M., \& Hare, J. W. (1995). Maternal Complications: Nephropathy, Neuropathy, and Coronary Artery Disease. In F. M. Brown \& J. W. Hare (Eds.), Diabetes Complicating Pregnancy: The Joslin Clinic Method (pp. 121-132). New York: Wiley-Liss, Inc.

Brydon, P., Smith, T., Proffitt, M., Gee, H., Holder, R., \& Dunne, F. (2000). Pregnancy outcome in women with Type 2 diabetes mellitus needs to be addressed. IJCP, 54(7), 418-419.

Casson, I. F., Clark, C. A., Howard, C. V., McKendrick, O., Pennycook, S., Pharoah, P., et al. (1997). Outcomes of pregnancy in insulin dependent diabetic women: results of a fiveyear population cohort study. BMJ, 315, 275-278.

Cundy, T., Slee, F., Gamble, G., \& Neale, L. (2002). Hypertensive disorders of pregnancy in women with Type 1 and Type 2 diabetes. Diabetic Medicine, 19, 482-489.

Dunne, F., Brydon, P., Smith, K., \& Gee, H. (2003). Pregnancy in women with Type 2 diabetes: 12 years outcome data 1990-2002. Diabetic Medicine, 20, 734-738.

Davey, R.X. (2003). Gestational diabetes in Victoria in 1996: incidence, risk factors and outcomes. MJA, 179, 118-119.

Expert Committee on the Diagnosis and Classification of Diabetes Mellitus. (2002). Report of the expert committee on the classification of diabetes mellitus. Diabetes Care, 25(Suppl. 1), S5-S17.

Farrell, T., Neale, L., \& Cundy, T. (2002). Congenital anomalies in the offspring of women with Type 1, Type 2 and gestational diabetes. Diabetic Medicine, 19, 322-326.

Franz, M. J. (Ed.). (2001). A Core Curriculum for Diabetes Education: Diabetes and Complications (4th ed.). Chicago: American Association of Diabetes Educators.

Harvard Health Publications. (2002). Pregnancy and Diabetes. A Special Health Report from Harvard Medical School (pp. 31-32). Boston, MA: Author.

Hawthorne, G., Irgens, L. M., \& Lie, R. T. (2000). Outcome of pregnancy in diabetic women in northeast England and in Norway, 1994-1997. BMJ, 321(7634), 730-731.

Hsu-Hage, B., \& Yang, X. (1999). Gestational diabetes mellitus and its complications. Asia Pacific Journal of Clinical Nutrition, 8(1), 82-89. 
Jensen, D. M., Sørensen, B., Feilberg-Jørgensen, N., Westergaard, J. G., \& Beck-Nielsen, H. (2000). Maternal and perinatal outcomes in 143 Danish women with gestational diabetes mellitus and 143 controls with a similar risk profile. Diabetic Medicine, 17, 281-286.

Jovanovic, L. (2001). What is so bad about a big baby? Diabetes Care, 24(8), 1317-1318.

Langer, O., \& Conway, D. L. (2000). Level of glycemia and perinatal outcome in pregestational diabetes. Journal of Maternal-Fetal Medicine, 9, 35-41.

Lauenborg, J., Mathiesen, E., Ovesen, P., Westergaard, J. G., Ekbom, P., Mølsted-Pedersen, L., et al. (2003). Audit on stillbirths in women with pregestational Type 1 diabetes. Diabetes Care, 26(5), 1385-1388.

Lee-Parritz, A., \& Heffner, L. J. (1995). Gestational diabetes. In F. M. Brown \& J. W. Hare (Eds.), Diabetes Complicating Pregnancy: The Joslin Clinic Method (pp. 16-40). New York: Wiley-Liss, Inc.

Loffredo, C. A., Wilson P. D., \& Ferencz, C. (2001). Maternal diabetes: an independent risk factor for major cardiovascular malformations with increased mortality of affected infants. Teratology, 64(2), 98-106.

Moore, L. L., Singer, M. R., Bradlee, M. L., Rothman, K. J., \& Milunsky, A. (2000). A prospective study of risk of congenital defects associated with maternal obesity and diabetes mellitus. Epidemiology, 11(6), 689-694.

Socioeconomic condition key influence on health status. (1999). Nation's Health 29, 13

Penny, G. C., Mair, G., \& Pearson, D. W. M. (2003). Outcomes of pregnancies in women with Type 1 diabetes in Scotland: a national population-based study. BJOG, 110, 315-318.

Platt, M. J., Stanisstreet, M., Casson, I. F., Howard, C. V., Walkinshaw, S., Pennycook, S., et al. (2002). St. Vincent's declaration 10 years on: outcomes of diabetic pregnancies. Diabetic Medicine, 19, 216-220.

Reeder, S. J., Martin, L. L., \& Koniak-Griffen, D. (1997). Maternity Nursing: Family, Newborn, and Women's Health Care (18th ed.). Philadelphia: Lippincott-Raven Publishers.

Rosenn, B. M., \& Miodovnik, M. (2000). Medical complications of diabetes mellitus in pregnancy. Clinical Obstetrics and Gynecology, 43(1), 17-29.

Sendag, F., Terek, M. C., Itil, I. M., Oztekin, K., \& Bilgin, O. (2001). Maternal and perinatal outcomes in women with gestational diabetes mellitus as compared to nondiabetic controls. The Journal of Reproductive Medicine, 46(12), 1057-1062.

Sibai, B. M., Caritis, S., Hauth, J., Lindheimer, M., VanDorsten, J. P., MacPherson, C., et al. (2000). Risks of preeclampsia and adverse neonatal outcomes among women with pregestational diabetes mellitus. American Journal of Obstetrics and Gynecology, 182(2), 364-368.

Svare, J. A., Hansen, B. B., \& Mølsted-Pedersen, L. (2001). Perinatal complications in women with gestational diabetes mellitus. Acta Obstet Gynecol Scand, 80, 899-904.

Thoenen, E., Gravely, M., Wright, J., \& Spiroff, J. (Eds.). (2001). The Burden of Diabetes in West Virginia. West Virginia Bureau for Public Health Department of Health and Human Resources. 
Thomas, C. L. (Ed.). (1977). Taber's Cyclopedic Medical Dictionary (13th ed.). Philadelphia: F.A. Davis Company.

U.S. Department of Health and Human Services. (1991) The International Classification of Diseases: $9^{\text {th }}$ Revison, Clinical Modification. $\left(4^{\text {th }}\right.$ ed., Vol. 1). (DHHS Publication No. $91-$ 1260). Washington, D.C.: U.S. Government Printing Office.

Uvena-Celebrezze, J., \& Catalano, P. M. (2000). The infant of the women with gestational diabetes mellitus. Clinical Obstetrics and Gynecology, 43(1), 127-138.

Väärasmäki, M., Gissler, M., Ritvanen, A., \& Hartikainen, A.-L. (2002). Congenital anomalies and first year surveillance in Type 1 diabetic births. Diabetic Medicine, 19, 589-593.

Wylie, B. R., Kong, J., Kozak, S. E., Marshall, C. J., On Tong, S., \& Thompson, D. M. (2002). Normal perinatal mortality in Type 1 diabetes mellitus in a series of 300 consecutive pregnancy outcomes. American Journal of Perinatology, 19(4), 169-176. 
APPENDIX A

IRB Exemption Form 


\section{Application for Exemption}

Approval from the IRB staff must be received prior to beginning the research described below. Please type this form with original signatures. All investigators must complete Ethics Training before an approval will be granted.

1. Title of study: Maternal Diabetes and Perinatal Outcomes

2. Investigators (list all investigators, principal investigator first; attach additional sheets if necessary):

\begin{tabular}{|c|c|c|c|c|}
\hline \multicolumn{2}{|c|}{ Name } & Dept/College & \multicolumn{2}{|c|}{ 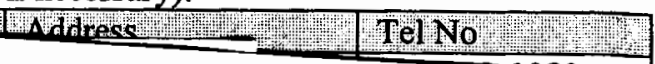 } \\
\hline Cecil Pollard & & \multicolumn{3}{|c|}{ Community Medicine } \\
\hline Rachael Gainor & & $\begin{array}{l}\text { Family and Consumer } \\
\text { Sciences/Davis College }\end{array}$ & & \\
\hline \\
\hline Name or nitials & & & Ethics Training & HPA A Training ${ }^{2}$ 霞 \\
\hline $\mathrm{CP}$ & \multicolumn{2}{|c|}{$=4$ YES if training has been completed } & Yes & Yes \\
\hline RG & \multicolumn{2}{|c|}{ 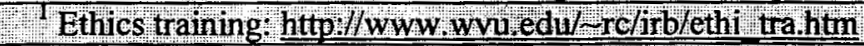 } & Yes & Yes \\
\hline & \multicolumn{2}{|c|}{${ }^{2}$ HIPAA info: htto:/www wyu,edu/rc/irb/index htm } & & \\
\hline
\end{tabular}

3. Estimated period of project or of human subject involvement: Starting date: N/A Ending date:

4. Reason for conducting research
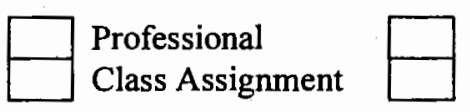

Dissertation Other

$\mathrm{X}$ Thesis

5. Source of funding (if applicable)

N/A

6. Number of projected subjects Number of projected records or data files

14,000

7. This research involves (check all that apply--see attached "Exempt Research" page):

$\mathrm{X}$ a Collection or study of existing data, documents, records or specimens, recorded without identifiers

b Normal educational practices conducted in established or commonly accepted educational settings

c Educational tests (cognitive, diagnostic, aptitude, achievement)

d Observation of public behavior

e Surveys, interviews or hand-outs for subjects over 18

(use age ranges, not actual age, for demographic information):

$\square$ Mail $\square$ Telephone $\square$ Person-to-person

Any possibility of identifying a subject (discuss in cover letter)

$\mathrm{g}$ The possibility that the subject's responses or conduct (if they became public) may place the subject at risk of criminal or civil liability or be damaging to the subject's financial standing or employability

Sensitive aspects of personal behavior (for example: illegal conduct, drug use, sexual behavior or use of alcohol)

Investigator's participation in activities being observed

Only surveys or interviews of elected or appointed public officials or candidates for public office

Audiotaping

Children under age 18 (see Chapter II of the Guidelines)

Note: Interviews and surveys with children are never exempt.

$\square \mathrm{m}$ Food tasting and evaluation

$\square$ n Research and demonstration projects

$\square$ o Access to protected health information (PHI) (See HIPAA requirements: http://www.wvu.edu/ rc/irb/index.htm)

8. Goal of research 
To test the hypothesis that negative birth outcomes are more commonly associated with pregnancies complicated by diabetes than those that are not.

Revised Dec 2003

9. Explanation of procedures involved in research

A secondary data analysis will be done of West Virginia birth records from 2001 and 2002 using West Virginia Vital Statistics Data and West Virginia Medicaid Claims Data.

10. Explanation of known risks to human subjects

N/A

11. Explanation of how records will be kept

HIPPA approved personnel who have been given the rights to use the Medicaid claims data will keep the data in a secure database within the WVU Office of Health Services Research. A database will be created that links the Medicaid and Vital Statistics data without using any identifiers for the purpose of Rachael Gainor's research.

A cover letter addressed to respondents must accompany any survey or questionnaire. The cover letter must be on the investigator's WVU departmental letterhead and must include the following:

1 a statement that the project is research being conducted in partial fulfillment of the requirements for a course, master's thesis, dissertation, etc.

2 purpose of study

3 a statement that subjects' responses will be kept anonymous or confidential (explain extent of confidentiality if subjects' names are requested)

4 if audiotaping, a statement that subject is being audiotaped (explain how tapes will be stored or disposed of during and after the study)

5 a statement that subjects do not have to answer every question

6 a statement that subject's class standing, grades, or job status (or status on an athletic team, if applicable) will not be affected by refusal to participate or by withdrawal from the study

7 a statement that participation is voluntary

Attachments:

questionnaire/survey to be used

telephone text (including introductory remarks as in a cover letter-see above)

cover letter

permission from external institution, on their letterhead (if applicable) 


\section{Data field being used for study}

\section{Medicaid Claims data for 2001-2002}

Diabetes-whether the woman was diabetic or not (according to ICD 9 codes)

Type-Pregestational or gestational diabetes (according to ICD 9 codes)

Vital Statistics Data for 2001-2002

Birth Date-year only

Sex of child-male/female code

Mother's age-numeric

Father's age-numeric

Mother's education level-numeric code

Father's education level-numeric code

Mother's race-white, black, other

Father's race-white, black, other

Number of previous births now living-numeric

Number of previous births now dead-numeric

Month prenatal care began-numeric code

Number of prenatal visits-numeric

Weight of child in lbs or grams-numeric

Estimated gestational age of the child-numeric code

APGAR scores for 1 minute-numeric code

APGAR scores for 2 minutes-numeric code

Medical risk factors of mother (listed by mother)-numeric code

Tobacco use-yes/no

Alcohol use-yes/no

Complications of labor and delivery-numeric code

Method of Delivery-numeric code

Abnormal Conditions of the newborn-numeric code

Congenital Anomalies-numeric code

Fetal loss-yes or no 
APPENDIX B

List of Complications of Labor and Delivery and Congenital Anomalies

From: West Virginia Vital Statistics Data Codes 
2001 Birth

Coding, Key Entry Procedures, and Record Format

\begin{tabular}{|c|c|c|c|}
\hline $\begin{array}{l}\text { (C_LAB_C) } \\
\text { Complications of } \\
\text { labor and/or deliveny } \\
\text { None [0] } \\
\text { Febrile[1] } \\
\text { Meconium } \\
\text { moderate/heavy [2] } \\
\text { Premature rupture } \\
\text { of membrane [3] } \\
\text { Abruptio } \\
\text { placenta [4] } \\
\text { Placenta previa [5] } \\
\text { Other excessive } \\
\text { bleeding [6] } \\
\text { Seizures during } \\
\text { labor [7] } \\
\text { Precipitous } \\
\text { labor [8] } \\
\text { Prolonged labor [9] }\end{array}$ & 17 & $\begin{array}{l}\text { Alphabetic } \\
\text { Marked ........................... Y } \\
\text { Not marked ................... Blank }\end{array}$ & $\begin{array}{l}\text { Select all that are given from the popup list.. } \\
\text { If no check boxes are check then C_LAB_C will be filled with } \\
\text { blanks. } \\
\text { Notes on how the C_LAB_C is stored. } \\
\text { C_LAB_C is stored as string with offset into the string used to } \\
\text { access each of the Complications of labor and/or delivery. The } \\
\text { positions are in the same order as they appear on the birth certificate } \\
\text { and in the NCHS documentation. The offsets are listed inside of the } \\
\text { [?] in the Item column. Think of it as an array with subscripts } \\
\text { starting a zero. } \\
\text { For example, Febrile is the } 2 \text { symbol in C_LAB_C and is normally } \\
\text { accessed as either C_LAB_C[1] or C_LAB_C+1. } \\
\text { Note: "None" moved. In } 1997 \text { it was just before "Other". } \\
\text { "None" is now the first choice listed. }\end{array}$ \\
\hline
\end{tabular}


2001 Birth

Coding, Key Entry Procedures, and Record Format

\begin{tabular}{|c|c|c|c|c|}
\hline $\begin{array}{l}\text { (Field Name) } \\
\text { Item }\end{array}$ & Length & $\begin{array}{l}\text { Source } \\
\text { Position }\end{array}$ & Code Structure & Coding and Key Entry Procedures \\
\hline $\begin{array}{l}\text { (C_LAB_C) } \\
\text { Complications of } \\
\text { labor and/or delivery } \\
\text { Dysfunctional } \\
\text { labor [10] } \\
\text { breech/mal- } \\
\text { presentation [11] } \\
\text { Cephalopelvic } \\
\text { disproportion [12] } \\
\text { Cord prolapse [13] } \\
\text { Anesthetic [14] } \\
\text { Fetal distress [15] } \\
\text { Other [16] }\end{array}$ & 17 & & $\begin{array}{l}\text { Alphabetic } \\
\text { Marked ........................ Y } \\
\text { Not marked ................... Blank }\end{array}$ & $\begin{array}{l}\text { Select all that are given from the popup list.. } \\
\text { If no check boxes are check then C_LAB_C will be filled with } \\
\text { blanks. } \\
\text { Notes on how the C_LAB_C is stored. } \\
\text { C_LAB_C is stored as string with offset into the string used to } \\
\text { access each of the Complications of labor and/or delivery. The } \\
\text { positions are in the same order as they appear on the birth certificate } \\
\text { and in the NCHS documentation. The offsets are listed inside of the } \\
\text { [?] in the Item column. Think of it as an array with subscripts } \\
\text { starting a zero. } \\
\text { For example, Febrile is the } 2 \text { symbol in C_LAB_C and is normally } \\
\text { accessed as either C_LAB_C[1] or C_LAB_C+1. } \\
\text { Note: "None" moved. In } 1997 \text { it was just before "Other". } \\
\text { "None" is now the first choice listed. }\end{array}$ \\
\hline $\begin{array}{l}\text { (C_LAB_C_O) } \\
\text { Complications of } \\
\text { labor and/or delivery } \\
\text { Other - Specified }\end{array}$ & 25 & & Text & $\begin{array}{l}\text { If in Complications of labor and/or delivery "Other" is checked then } \\
\text { a box will popup asking you to enter what the other was. What } \\
\text { every you type into this box is stored in C_LAB_C_O. }\end{array}$ \\
\hline
\end{tabular}


2001 Birth

Coding, Key Entry Procedures, and Record Format

\begin{tabular}{|c|c|c|c|}
\hline $\begin{array}{l}\text { (ABN_C_C_O) } \\
\text { Abnormal conditions } \\
\text { of the newborn } \\
\text { Other - Specified }\end{array}$ & 25 & Text & $\begin{array}{l}\text { If in Abnormal conditions of the newborn "Other" is checked then a } \\
\text { box will popup asking you to enter what the other was. What every } \\
\text { you type into this box is stored in ABN_C_C_O. }\end{array}$ \\
\hline $\begin{array}{l}\text { (CONG_A_C) } \\
\text { Congenital Anomalies } \\
\text { None [0] } \\
\text { Anencephalus [1] } \\
\text { Spinal Bifida / } \\
\text { Meningocele [2] } \\
\text { Hydrocephalus [3] } \\
\text { Microcephalus [4] } \\
\text { Other central } \\
\text { nervous system } \\
\text { anomalies [5] } \\
\text { Heart mal- } \\
\text { formations [6] }\end{array}$ & 23 & $\begin{array}{l}\text { Alphabetic } \\
\text { Marked ......................... Y } \\
\text { Not marked ................... Blank }\end{array}$ & $\begin{array}{l}\text { Select all that are given from the popup list.. } \\
\text { If no check boxes are check then congenital anomalies will be filled } \\
\text { with blanks. } \\
\text { Notes on how the CONG_A_C is stored. } \\
\text { CONG_A_C is stored as string with offset into the string used to } \\
\text { access each of the congenital anomalies. The positions are in the } \\
\text { same order as they appear on the birth certificate and in the NCHS } \\
\text { documentation. The offsets are listed inside of the [?] in the Item } \\
\text { column. Think of it as an array with subscripts starting a zero. } \\
\text { For example, Microcephalus is the } 5 \text { symbol in CONG_A_C and is } \\
\text { normally accessed as either CONG_A_C[4] or CONG_A_C+4. } \\
\text { Note: "None" moved. In } 1997 \text { it was just before "Other". } \\
\text { "None" is now the first choice listed. }\end{array}$ \\
\hline
\end{tabular}


2001 Birth

Coding, Key Entry Procedures, and Record Format

\begin{tabular}{|c|c|c|c|c|}
\hline $\begin{array}{l}\text { (Field Name) } \\
\text { Item }\end{array}$ & Length & $\begin{array}{l}\text { Source } \\
\text { Position }\end{array}$ & Code Structure & Coding and Key Entry Procedures \\
\hline $\begin{array}{l}\text { (CONG_A_C) } \\
\text { Congenital Anomalies } \\
\text { Other circulatory } \\
\text { respiratory } \\
\text { anomalies [7] } \\
\text { Rectal atresia / } \\
\text { stenosis [8] } \\
\text { Tracheo } \\
\text { esophageal } \\
\text { fistula / } \\
\text { esophageal } \\
\text { atresia [9] } \\
\text { Omphalocole / } \\
\text { Gastroschisis [10] } \\
\text { Other gastro- } \\
\text { intestinal } \\
\text { anomalies [11] } \\
\text { Malformed } \\
\text { genitalia [12] }\end{array}$ & 23 & & $\begin{array}{l}\text { Alphabetic } \\
\text { Marked .......................... Y } \\
\text { Not marked ................... Blank }\end{array}$ & $\begin{array}{l}\text { Select all that are given from the popup list.. } \\
\text { If no check boxes are check then congenital anomalies will be filled } \\
\text { with blanks. } \\
\text { Notes on how the CONG_A_C is stored. } \\
\text { CONG_A_C is stored as string with offset into the string used to } \\
\text { access each of the congenital anomalies. The positions are in the } \\
\text { same order as they appear on the birth certificate and in the NCHS } \\
\text { documentation. The offsets are listed inside of the [?] in the Item } \\
\text { column. Think of it as an array with subscripts starting a zero. } \\
\text { For example, Microcephalus is the } 5 \text { symbol in CONG_A_C and is } \\
\text { normally accessed as either CONG_A_C[4] or CONG_A_C+4. } \\
\text { Note: "None" moved. In } 1997 \text { it was just before "Other". } \\
\text { "None" is now the first choice listed. }\end{array}$ \\
\hline
\end{tabular}


Coding, Key Entry Procedures, and Record Format

\begin{tabular}{|c|c|c|c|c|}
\hline $\begin{array}{l}\text { (Field Name) } \\
\text { Item }\end{array}$ & Length & $\begin{array}{l}\text { Source } \\
\text { Position }\end{array}$ & Code Structure & Coding and Key Entry Procedures \\
\hline $\begin{array}{l}\text { (CONG_A_C) } \\
\text { Congenital Anomalies } \\
\text { Renal } \\
\text { agenesis [13] } \\
\text { Other urogenital } \\
\text { anomalies [14] } \\
\text { Cleft lip / } \\
\text { palate [15] } \\
\text { Polydactyly / } \\
\text { Syndactyly / } \\
\text { Adactyly [16] } \\
\text { Club foot [17] } \\
\text { Diaphragmatic } \\
\text { hernia [18] } \\
\text { Other musculo- } \\
\text { skeletal / } \\
\text { integumental } \\
\text { anomalies [19] }\end{array}$ & 23 & & $\begin{array}{l}\text { Alphabetic } \\
\text { Marked ......................... Y } \\
\text { Not marked ................... Blank }\end{array}$ & $\begin{array}{l}\text { Select all that are given from the popup list.. } \\
\text { If no check boxes are check then congenital anomalies will be filled } \\
\text { with blanks. } \\
\text { Notes on how the CONG_A_C is stored. } \\
\text { CONG_A_C is stored as string with offset into the string used to } \\
\text { access each of the congenital anomalies. The positions are in the } \\
\text { same order as they appear on the birth certificate and in the NCHS } \\
\text { documentation. The offsets are listed inside of the [?] in the Item } \\
\text { column. Think of it as an array with subscripts starting a zero. } \\
\text { For example, Microcephalus is the } 5 \text { symbol in CONG_A_C and is } \\
\text { normally accessed as either CONG_A_C[4] or CONG_A_C+4. } \\
\text { Note: "None" moved. In } 1997 \text { it was just before "Other". } \\
\text { "None" is now the first choice listed. }\end{array}$ \\
\hline
\end{tabular}


Coding, Key Entry Procedures, and Record Format

\begin{tabular}{|c|c|c|c|c|}
\hline $\begin{array}{l}\text { (Field Name) } \\
\text { Item }\end{array}$ & Length & $\begin{array}{l}\text { Source } \\
\text { Position }\end{array}$ & Code Structure & Coding and Key Entry Procedures \\
\hline $\begin{array}{l}\text { (CONG_A_C) } \\
\text { Congenital Anomalies } \\
\text { Down's } \\
\text { syndrome [20] } \\
\text { Other chromosomal } \\
\text { anomalies [21] } \\
\text { Other [22] }\end{array}$ & 23 & & $\begin{array}{l}\text { Alphabetic } \\
\text { Marked ........................ Y } \\
\text { Not marked .................. Blank }\end{array}$ & $\begin{array}{l}\text { Select all that are given from the popup list.. } \\
\text { If no check boxes are check then congenital anomalies will be filled } \\
\text { with blanks. } \\
\text { Notes on how the CONG_A_C is stored. } \\
\text { CONG_A_C is stored as string with offset into the string used to } \\
\text { access each of the congenital anomalies. The positions are in the } \\
\text { same order as they appear on the birth certificate and in the NCHS } \\
\text { documentation. The offsets are listed inside of the [?] in the Item } \\
\text { column. Think of it as an array with subscripts starting a zero. } \\
\text { For example, Microcephalus is the } 5 \text { symbol in CONG_A_C and is } \\
\text { normally accessed as either CONG_A_C[4] or CONG_A_C+4. } \\
\text { Note: "None" moved. In } 1997 \text { it was just before "Other". } \\
\text { "None" is now the first choice listed. }\end{array}$ \\
\hline $\begin{array}{l}\text { (CONG_A_C05) } \\
\text { Congenital Anomalies } \\
\text { Other central nervous } \\
\text { system - Specified }\end{array}$ & 25 & & Text & $\begin{array}{l}\text { If in congenital anomalies "Other central nervous system" is checked } \\
\text { then a box will popup asking you to enter what the other was. What } \\
\text { every you type into this box is stored in CONG_A_C05. }\end{array}$ \\
\hline
\end{tabular}




\section{VITA}

In May of 2001 I received a Bachelor of Arts degree in Secondary Education with a specialization in Family and Consumer Sciences from Fairmont State College (FSC) in Fairmont, West Virginia. While at FSC I served as vice president as well as president of the FSC Family and Consumer Sciences Club. I was also a Freshman Orientation Counselor in the Fall of 2001. I was a member of the WV Association of Family and Consumer Sciences, a member of the American Association of Family and Consumer Sciences and a member of the American Association of Family and Consumer Sciences Educators.

I entered graduate school at West Virginia University (WVU) in the spring of 2002 in the Masters of Science program of Family and Consumer Sciences specializing in Child Development and Family Studies. I was initiated as a member of Phi Omicron Epsilon, which is the National Honor Society for Family and Consumer Sciences in the spring of 2003 and was initiated as a member of Gamma Sigma Delta, the National Honor Society of Agriculture and Forestry in April of 2004. I will graduate from WVU in May of 2004.

While attending WVU I worked as a graduate assistant at the WVU Office of Health Services Research. During my assistantship there I had the opportunity to work in a variety of health fields including nutrition, diabetes, smoking cessation, cardiovascular disease, domestic abuse and child maltreatment, and rural health needs. I have attended several professional conferences pertaining to these fields including the WV Diabetes Symposium, the WV Rural Health Education Partners Conference and the WV State Health Educators Coalition Conference.

In 2002 I wrote and implemented a West Virginia Community Based Initiatives grant for $\$ 20,000$, which is funded through the West Virginia Bureau for Public Health. The grant, titled "Gardening for Good Nutrition," was a nutrition-based project and was aimed at preschool aged children. The project taught the preschoolers the importance of eating vegetables everyday through educational materials and creative curricula. The children were also educated about the "ins and outs" of vegetables through vegetable gardens that they helped to grow and harvest at their school. 